\title{
Why $g$ Matters: The Complexity of Everyday Life
}

\author{
LINDA S. GOTTFREDSON \\ University of Delaware
}

\begin{abstract}
Personnel selection research provides much evidence that intelligence $(g)$ is an important predictor of performance in training and on the job, especially in higher level work. This article provides evidence that $g$ has pervasive utility in work settings because it is essentially the ability to deal with cognitive complexity, in particular, with complex information processing. The more complex a work task, the greater the advantages that higher $g$ confers in performing it well. Everyday tasks, like job duties, also differ in their level of complexity. The importance of intelligence therefore differs systematically across different arenas of social life as well as economic endeavor. Data from the National Adult Literacy Survey are used to show how higher levels of cognitive ability systematically improve individuals' odds of dealing successfully with the ordinary demands of modern life (such as banking, using maps and transportation schedules, reading and understanding forms, interpreting news articles). These and other data are summarized to illustrate how the advantages of higher $g$, even when they are small, cumulate to affect the overall life chances of individuals at different ranges of the IQ bell curve. The article concludes by suggesting ways to reduce the risks for low-IQ individuals of being left behind by an increasingly complex postindustrial economy.
\end{abstract}

"Intelligence is important in social life." Few claims in the social sciences are backed by such massive evidence but remain so hotly contested in public discourse. One obvious reason for such dispute is that many Americans are unsettled by the possible social ramifications of the claim, accurate or not. Another reason is that intelligence remains for many people an abstraction unconnected to their personal experience-a mere "black box" that they can fill with any imagining.

The aim of this article is to clarify the relevance of general intelligence (specifically, $g$ ) in everyday life-in other words, to demystify that black box. Besides demonstrating that $g$ is important in practical affairs, I seek to demonstrate why intelligence has such surprisingly pervasive importance in the lives of individuals.

Virtually all research on intelligence contributes to our understanding of its meaning. Indeed, thousands of studies have provided, and continue to provide, evidence about the origins of intelligence, its course of development, constituent

Direct all correspondence to: Linda S. Gottfredson, College of Human Resources, Education, and Public Policy, University of Delaware, Newark, DE 19716.

INTELLIGENCE 24(1) 79-132

ISSN: 0160-2896
Copyright (C) 1997 Ablex Publishing Corporation All rights of reproduction in any form reserved 
mental processes, degree of malleability, impact on performance in training and education, and the like (e.g., see the bibliography published with the editorial in this issue). However, relatively little attention has been devoted to the meaning of intelligence as individuals go about their daily lives. There is, nonetheless, considerable evidence pertinent to the issue.

I begin by focusing on the extensive research in job performance and job analysis. This work demonstrates that intelligence is important outside school settings, but it also reveals why it has practical utility. As will be shown, paid employment often consists of tasks that many people perform in their daily lives, so the research also provides a window into the cognitive demands of everyday life and hence the utility of $g$ across perhaps all of life's settings.

Next, I draw on the National Adult Literacy Survey (NALS) to provide more specific examples of the everyday tasks for which higher intelligence constitutes a substantial advantage. I then use both the employment and literacy data to sketch a portrait of life's challenges and opportunities at different levels of intelligence. Lastly, I compare trends in the supply of national intelligence with trends in the demand for it and what they may portend for individuals at different levels of the IQ continuum.

\section{WHAT DOES "IMPORTANT" MEAN?}

By importance I mean functional importance. For example, to what extent does being brighter typically enhance academic achievement or job performance? To what extent will a firm's aggregate worker productivity rise if it selects brighter employees? My concern here is thus with the impact of actual capabilities, not with people's perceptions of their existence, utility, or moral value. Intelligence is viewed here, not as a virtue in itself, but as a means to commonly valued social ends.

The most common ways of indexing functional importance involve calculating correlations between individuals' levels of intelligence and their degrees of success on some criterion. (These correlations are also called validities, predictive validities, or validity coefficients.) The higher the correlation, the more important a predictor is generally said to be.

Three sorts of statistics, however, can be calculated from correlations in order to facilitate their interpretation for different purposes: predictive efficiency, prediction of individuals' odds of success, and prediction of changes in groups' aggregate levels of performance (Jensen, 1980, pp. 305-310). I describe them in the Appendix, because there is much confusion on the issue. The latter two are the most important for social policy purposes. As will be illustrated, even small correlations can yield huge differences in individuals' life chances. 


\section{$g$ MATTERS ON THE JOB}

The nature of intelligence--specifically, the general mental ability factor $g$ derived from factor analyses of large sets of diverse mental tests-is discussed in detail later. It is sufficient at this point to note that it is a highly general information-processing capacity that facilitates reasoning, problem solving, decision making, and other higher order thinking skills.

Research in job analysis and personnel selection refutes the claim that $g$ is useful only in academic pursuits. Intelligence turns out to be more important in predicting job performance than even personnel psychologists thought just two decades ago. And, very importantly, the research allows strong inferences about its causal importance.

\section{Illustrative Correlational Data}

Civil rights law and regulation have led many employers in recent decades to scrutinize more carefully the validity of their selection procedures (Sharf, 1988). They have also prompted a sometimes desperate search for less $g$-loaded selection procedures (procedures less highly correlated with intelligence) in order to reduce disparate impact of selection devices on minority hiring and thus employers' vulnerability to employment discrimination lawsuits (Gottfredson \& Sharf, 1988). As a result, there now exists a very large body of evidence concerning the predictive validity of various mental aptitudes, personality traits, and physical capabilities (e.g., see Gottfredson, 1986b; J. Hogan, 1991; R. Hogan, 1991; Landy, Shankster, \& Kohler, 1994; Lubinski \& Dawis, 1992; Schmidt, Ones, \& Hunter, 1992; Stokes, Mumford, \& Owens, 1994). Many of these data have been metaanalyzed.

Predictive Validity of $\mathrm{g}$ Is Ubiquitous. The key observation here is that personnel psychologists no longer dispute the conclusion that $g$ helps to predict performance in most if not all jobs (Hartigan \& Wigdor, 1989). Rather, their disputes concern how large the predictive validities are, often in the context of deciding the appropriate composition of a personnel selection battery. Estimates of the average validity of $g$ across all jobs in the economy generally range between .3 and .5 (on a scale from 0 to 1.0), depending on how validities are corrected for unreliability in the criterion and restriction in range on the predictor (Hartigan \& Wigdor, 1989).

These estimates are based primarily on studies that used supervisor ratings of job performance. Average validities are yet higher when performance is measured objectively. For example, Hunter (1986) reported that correlations of $g$-loaded tests with work sample ("hands-on") performance versus supervisor ratings were .75 versus .47 in a sample of civilian jobs and .53 versus .24 for a range of 
military jobs. Validities vary widely across different kinds of jobs, from a low of about .2 to a high of .8 .

Predictive Validities of $\mathbf{g}$ Rise With Job Complexity. An especially important observation is that predictive validities vary systematically according to the overall complexity of the work involved. Hunter $(1983,1986)$ demonstrated this clearly with U.S. Employment Service General Aptitude Test Battery (GATB) validity data for 515 occupations (see also Gutenberg, Arvey, Osburn, \& Jeanneret, 1983). As shown in Table 1, Hunter classified this diverse set of occupations into five general job families, three according to their Dictionary of Occupational Titles (U.S. Department of Labor, 1977) ratings for complexity of dealings with data (high, medium, and low) and two industrial groups (complex "set-up" work and simple "feeding/offbearing" work) according to their complexity of dealings with things. The validity of cognitive ability (corrected for unreliability and restriction in range) for predicting job performance rose from .23 for the low complexity "feeding/offbearing" jobs to $.40, .51$, and .58 , respectively, for the low, medium, and high "data" complexity job families. The predictive validity of cognitive ability for set-up work was also high, .56.

Jobs need not be academic for higher levels of $g$ to enhance performance (i.e.,

TABLE 1

Predictive Validity of Intelligence in Jobs of Different Complexity ${ }^{a}$

\begin{tabular}{|c|c|c|}
\hline & \multicolumn{2}{|c|}{ Validity for: } \\
\hline & Performance & Training \\
\hline \multicolumn{3}{|l|}{ General job families } \\
\hline Iligh complexity & .58 & .50 \\
\hline Medium complexityc & .51 & .57 \\
\hline Low complexityd & .40 & .54 \\
\hline \multicolumn{3}{|l|}{ Industrial families } \\
\hline Precision set-upe & .56 & .65 \\
\hline Feeding/offbearing $\mathrm{f}$ & .23 & - \\
\hline
\end{tabular}

aMeta-analysis of 515 validation studies conducted by the U.S. Employment Service (Hunter, 1983; Hunter \& Hunter, 1984), 425 of job performance $(32,124$ workers) and 90 of training success (6496 workers). Reprinted by permission of Academic Press.

bE.g., retail food manager, fish and game warden, biologist, city circulation manager. DOT "data" equals 0 or 1 .

'E.g., automotive mechanic, radiologic technician, automotive parts counterman, high school teacher. DOT "data" equals 2-4.

dE.g, , assembler, insulating machine operator, forklift truck operator. DOT "data" equals 5 or 6 .

eE.g., machinist, cabinetmaker, metal fabricator. DOT "things" equals 0 .

f E.g., shrimp picker, corn-husking machine operator, cannery worker, spot welder. DOT "things" equals 6. 
to be $g$ loaded). Clerical occupations and the skilled trades are both moderately $g$ loaded, but the latter have always been considered "hand" rather than "head" occupations. To illustrate the complexity of many "nonacademic" jobs, Hunter's medium complexity job family includes auto mechanics; similarly, the even more highly g-loaded industrial set-up work is typified by jobs such as machinist and cabinetmaker.

Other data indicate that even the most intellectually demanding work is not necessarily academic. Professionals and high-level executives both rate their occupations as highly intellectually demanding, but only the former tend to rate educational credentials, reading, and writing as essential (Gottfredson, Finucci, \& Childs, 1984). Consistent with this, dyslexic men of high intelligence and social class frequently hold high-level jobs but rarely enter ones in which reading, writing, and educational credentials are critical (Gottfredson et al., 1984). (Dyslexics are notable precisely because they do not have the reading and spelling skills, despite exposure to learning them, that normally accompany intelligence.)

Validity of $\mathrm{g}$ Is High Relative to Other Predictors. $g$ can be said to be the most powerful single predictor of overall job performance. First, no other measured trait, except perhaps conscientiousness (Landy et al., 1994, pp. 271, 273), has such general utility across the sweep of jobs in the U.S. economy. More specific personality traits and aptitudes, such as extraversion or spatial aptitude, sometimes seem essential above and beyond $g$, but across a more limited range of jobs (e.g., Barrick \& Mount, 1991; Gottfredson, 1986a).

Second, no other single predictor measured to date (specific aptitude, personality, education, experience) seems to have such consistently high predictive validities for job performance. The clearest exceptions to the predictive superiority of $g$ prove its relative importance. Psychomotor aptitudes sometimes have higher predictive validities than $g$, but only in low-level work (validities for $g$ and psychomotor aptitudes vary inversely with each other; Gottfredson, 1986a; Hunter \& Hunter, 1984). Validities for experience can also sometimes rival those for $g$, but, once again, they fall as complexity increases (McDaniel, Schmidt, \& Hunter, 1988). In addition, they fall (whereas those for $g$ do not) as groups gain longer average job tenure (Schmidt, Hunter, Outerbridge, \& Goff, 1988). The advantages of superior experience fade-but those of superior $g$ do not-in more experienced groups of workers. In short, there is no rival to $g$ in predicting performance in complex jobs. Average validity coefficients for educational level (0.0 to .2) are inconsequential relative to those for $g$ (Hunter \& Hunter, 1984).

Third, $g$ generally predicts training and job performance about as well as whole batteries of predictors and, in any case, "carries the freight of prediction" in those batteries (Jensen, 1980, pp. 347-349; Ree, Earles, \& Teachout, 1994; Thomdike, 1986). Less cognitive traits such as personality and interests may better predict the less central dimensions of job performance, but this exception once 
again proves the relative importance of $g$. The Army's Project A provides the most definitive evidence in this regard (McHenry, Hough, Toquam, Hanson, \& Ashworth, 1990). As shown in Table 2, specific aptitudes, interests, and traits of personality and temperament do not add meaningfully to the ability of general cognitive ability to predict either core technical proficiency or general proficiency in soldiering; they raise (corrected) validities only from .63 to .65 for the former and from .65 to .68 for the latter. Personality and temperament are at least as powerful as $g$, however, in predicting "personal discipline" and "physical fitness and military bearing." They raise multiple correlations for these two auxilliary performance dimensions from .17 and .22 , respectively, to .35 and .41 .

Recent efforts to model job performance have begun to clarify the role of $g$. Path models of training and job proficiency (mostly in military jobs) indicate that $g$ strongly predicts success in training and acquiring job knowledge, which in turn strongly predict task proficiency (Borman, White, Pulakos, \& Oppler, 1991; Borman, Hanson, Oppler, Pulakos, \& White, 1993; Borman, White, \& Dorsey, 1995; Hunter, 1983; Ree, Carretta, \& Teachout, 1995; Schmidt, Hunter, \& Outerbridge, 1986).

The nature of the job and its context seem to determine whether $g$ has any direct effect on task proficiency, net of job knowlege. To illustrate, $g$ has no direct effect in the nonsupervisory military jobs studied to date, where "performance requirements are laid out in great detail in technical manuals and training programs" (Ree et al., 1995, p. 728), and workers are expected to "go by the book" (Hunter, 1986; Schmidt et al., 1986). By contrast, $g$ has been found to have a direct effect, net of job knowledge, in civilian jobs (Hunter, 1983) and supervisory military jobs, where there is perhaps "more frequent, direct use of ability" (Borman et al., 1993, p. 447).

Length of experience has weak to moderate effects on job knowledge and task proficiency, net of $g$ (Borman et al., 1993). Experience has its largest effects, as noted earlier, in less complex jobs, which are typically learned through experience rather than training (Schmidt et al., 1986).

g Is Important in a Causal Sense. Perhaps no firm conclusions about the causal importance of $g$ can be drawn when it is measured concurrently with job performance, as has often been the case with large civilian testing programs, such as the U.S. Employment Service's General Aptitude Test Battery (GATB; U.S. Department of Labor, 1970). However, cognitive ability is always measured prior to induction into the military. The military has provided considerable evidence during the past half century for the causal importance of $g$.

World War II offers an early demonstration. During a period when it had to train many thousands of pilots, the military experimented with admitting to pilot training inductees of all ability levels (Matarazzo, 1972, p. 163). Of men in the top stanine of the experimental selection battery, which included abilities and 


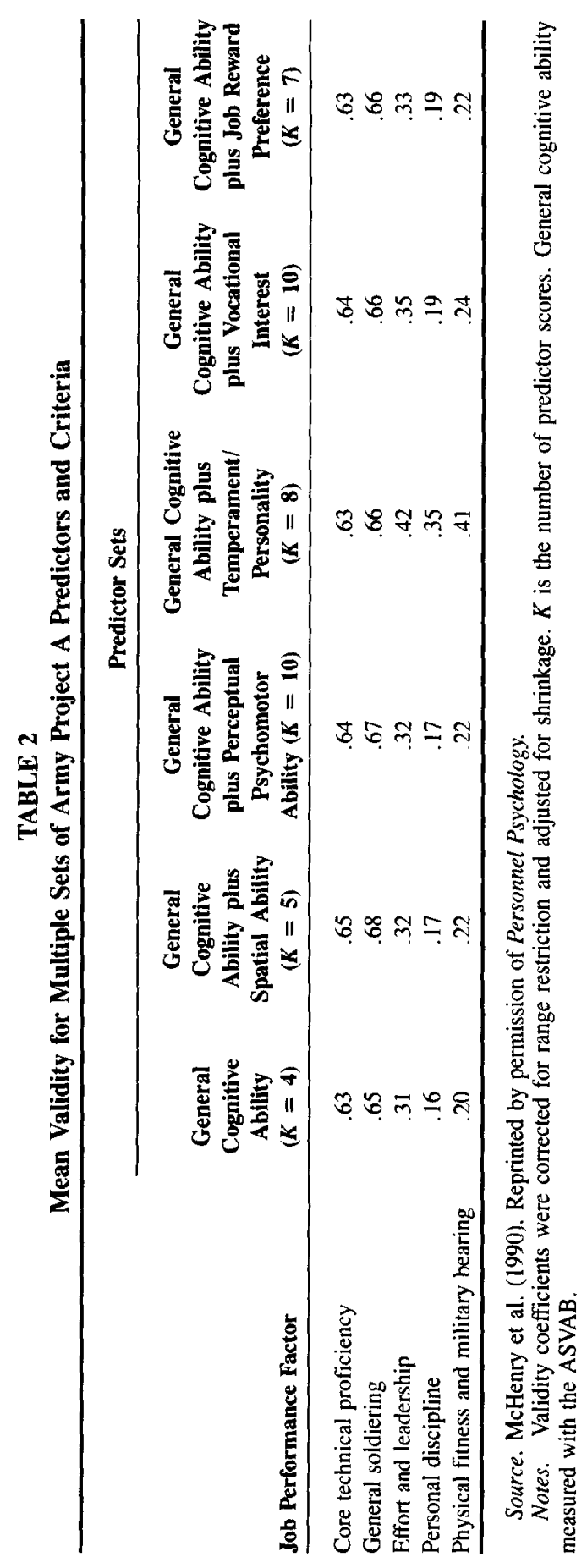


motivation measured at induction, $95 \%$ successfully completed training, whereas only $20 \%$ of those in the lowest stanine did so. Subsequent military research has consistently shown that highly $g$-loaded measures such as the Armed Forces Qualifying Test (AFQT) and its forerunners, although not always conceptualized as measures of $g$, are good measures of "trainability"-hence their long-time use in screening for enlistment and assignment to training programs. More recent work, such as Army Project A (McHenry et al., 1990), has carefully demonstrated the validity of such measures for predicting job performance itself in military specialties.

Additional evidence of the causal importance of $g$ is provided by the many unsuccessful efforts to eliminate or short-circuil its functional link (correlation) with job proficiency. For example, there have been efforts to train the general cognitive skills that $g$ naturally provides and that jobs require-such as general reading comprehension (which is important for using work manuals, interpreting instructions, and the like). Another approach has been to provide extra instruction or experience to very low-aptitude individuals so that they have more time to master job content. Both reflect what might be termed the training hypothesis, which is that, with sufficient instruction, low-aptitude individuals can be trained to perform as well as high-aptitude individuals. The armed services have devoted much research to such efforts, partly because they periodically have had to induct large numbers of very low-aptitude recruits. Even the most optimistic observers (Sticht, 1975; Sticht, Armstrong, Hickey, \& Caylor, 1987) have concluded that such training fails to improve general skills and, at most, increases the number of lowaptitude men who perform at minimally acceptable levels, mostly in lower level jobs.

Not even lengthy experience (5 years) eliminates differences in overall job performance between more and less bright men (Schmidt et al., 1988). A large study of military cooks, repairmen, supply specialists, and armor crewmen showed that performance may converge on simpler and oft-performed tasks (Vineberg \& Taylor, 1972, p. 55-57). However, even that limited convergence took considerable time, reflecting large differences in trainability. It took men in the 10th to 30th percentiles of ability about 12 to 24 months to catch up with the performance levels on those tasks that were exhibited by men above the 30 th percentile with no more than 3 months' experience on the job. These findings from field settings are consistent with Ackerman's (1987) review of the experimental literature relating skill learning and ability: individual differences in performance do not decrease with practice, and sometimes increase, when tasks are characterized by "predominantly inconsistent or varied information processing requirements." In short, tasks that are not easily routinized continue to call forth $g$.

Finally, even individuals who argue most systematically that work environments influence intelligence have estimated, using linear equation modeling, that intelligence affects the complexity of work one performs much more than the 
reverse (Schooler, 1984). This conclusion is buttressed by evidence that intelligence is highly stable beginning in childhood (Moffitt, Caspi, Harkness, \& Silva, 1993), has not been permanently affected by interventions specifically designed to raise it (Jensen, 1989a; Spitz, 1986), and has high (within-race) heritability but negligible "shared environmentability" by early adulthood (Plomin \& Petrill, 1997; Rowe, 1997).

The causal impact of $g$ does not mean, of course, that it is the only cause of differences in job performance. Other personal and environmental attributes clearly matter. However, the evidence is overwhelming that differences in intelligence are a major source of enduring, consequential differences in job performance.

\section{Criterion-Referenced Data}

The concrete meaning of higher versus lower intelligence on the job-and in everyday life-is better illustrated by linking IQ levels to specific job proficiency levels, that is, by providing criterion-referenced data. For example, what exactly can workers of different ability levels do, and how quickly and accurately can they learn to do it? Disappointingly little such information has been published, but the manuals and reports for the major employment testing programs, civilian and military, provide a good start in piecing together criterion-related interpretations. All such programs provide measures of $g$, although they are not always labeled as such.

I focus mostly on data from the Wonderlic Personnel Test (WPT), which is a 50-item intelligence test that many employers have used to screen job applicants. Its validity and reliability for this purpose compare favorably with other adult intelligence tests. The manual for the Wonderlic provides the most comprehensive, up-to-date and publicly available data on the $g$ demands of a wide variety of civilian jobs.

Higher Levels of $\mathrm{g}$ Are Required up the Occupational Ladder. Figure 1 presents data from the Wonderlic Personnel Test. It illustrates the broad pattern documented by the big military and civilian testing programs during the first half of this century (see Matarazzo, 1972, chap. 7, for a summary).

The first observation is that there is much IQ variation within all occupations and much overlap among them. Occupations attract and accommodate individuals from a wide range of IQ levels. As Figure 1 shows, the middle 50\% of applicants to a job generally covers a range of 15 to 20 IQ points.

Applicants to particular jobs are somewhat more homogeneous than the general working population: specifically, the median $S D$ of WPT scores of applicants to the specific occupations shown in Figure 1 (6.3 WPT points) is $83 \%$ of that for the entire working population (7.6; Wonderlic Personnel Test, 1992, pp. 25, 27; but see also Sackett and Ostgaard, 1994, p. 682). (The data in Figure 3 suggest, 


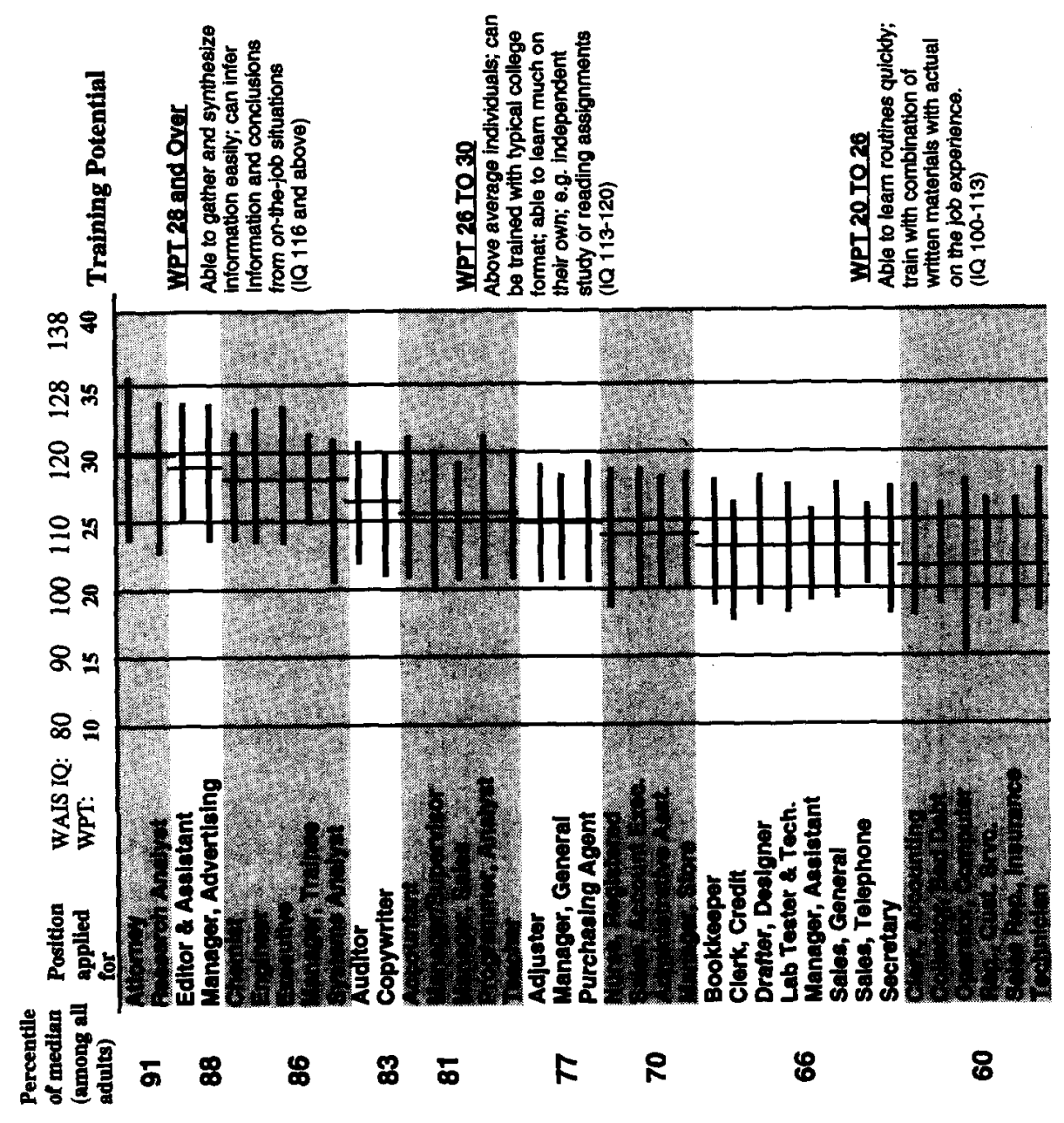




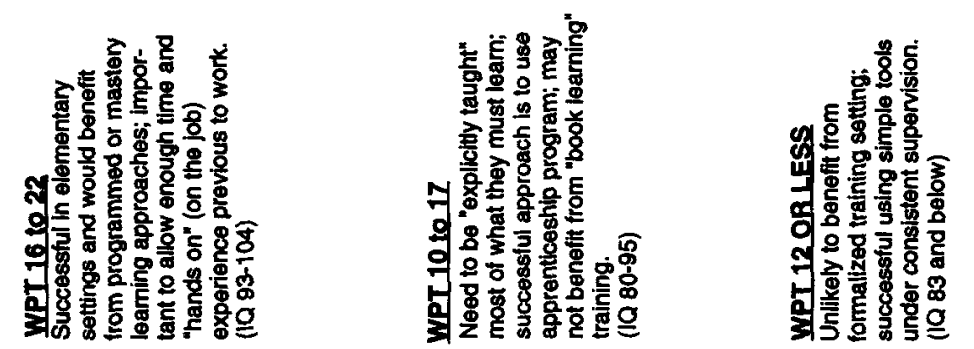

案吉吉

焉

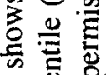

怘通

둥

है

产 岂

흥 초

8 क

总资

틋ㅇ

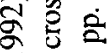

듬

홍

원

客造

跤

8

雚

无吉宫

융 몽용

总

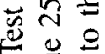

용

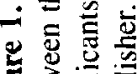

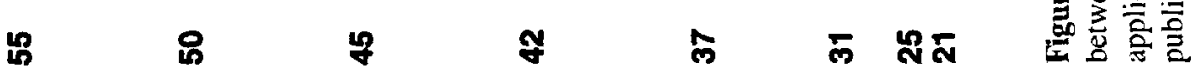


however, that the general working population disproportionately excludes low-IQ individuals.)

Job incumbents, in turn, are more homogeneous than applicants: the $S D$ of job incumbents on ability tests is .6 to .7 of that for applicants (Hunter, Schmidt, \& Judiesch, 1990)-but they still range widely in ability. Translating these data into the IQ metric, the average $S D$ among incumbents in an occupation is between about 7.5 and 8.7 IQ points (compared with 15 for the general population). This means that two thirds of incumbents in the average job fall within a range of 15 to 17 IQ points; over $95 \%$ would be within a range of 30 to 34 points.

The second important observation, however, is that there are striking differences in the IQ ranges from which occupations tend to draw the bulk of their workers. More specifically, there appear to be minimum IQ thresholds that rise steadily with job level. The median of an applicant pool is often recommended as a minimum passing score for further consideration of applicants to that job (Wonderlic Personnel Test, 1992, p. 14), so it can be viewed as a threshold for applicant competitiveness. By this measure, one needs an IQ of about 120 (the 91 st percentile of the general population) to be competitive for the highest level jobs in Figure 1 (research analyst and advertising manager). The IQ levels required for competitiveness drop with job level: for example, IQ 112 (81st percentile of the general adult population) for accountant and teacher; IQ 100 (50th percentile) for cashier, meter reader, and teller; IQ 90 (25th percentile) for custodian and material handler. The medians of the highest and lowest of these applicant IQ distributions (IQ 120 vs. 90) differ by $2 S D$, which means these distributions do not overlap much.

If the 25th WPT percentile of applicants is used to estimate the minimum threshold for employability in an occupation, it suggests that virtually all occupations accommodate individuals down to IQ 110 , but virtually none routinely accommodates individuals below IQ 80 (WPT 10). Employment options drop dramatically with IQ-from virtually unlimited above IQ 120 to scant below IQ 80. Such options are virtually nonexistent today (except in sheltered settings) for individuals below IQ 70 to 75 , the usual threshold for borderline mental retardation.

Lest IQ 80 seem an unreasonably high (i.e., exclusionary) threshold in hiring, it should be noted that the military is prohibited by law (except under a declaration of war) from enlisting recruits below that level (the 10th percentile). That law was enacted because of the extraordinarily high training costs and high rates of failure among such men during the mobilization of forces in World War II (Laurence \& Ramsberger, 1991; Sticht et al., 1987; U.S. Department of the Army, 1965). Minimum enlistment standards since World War II have generally been higher than the 10th percentile, and closer to what they are today for the different services: the 16th AFQT percentile (Army, about IQ 85), 21st (Marine Corps and Air Force, IQ 88), and 27th (Navy, IQ 91). It should be noted that these are the enlistment standards for high school graduates. Nongraduates must score above 
the 27th to 65th percentiles on the AFQT, depending on the service in question (Laurence \& Ramsberger, 1991, p. 11).

Higher g Reflects Higher Trainability. IQ 75 to 80 thus seems to define the threshold below which individuals risk being unemployable in modern economies. This secming lowcr boundary of today's occupational order becomes more understandable when considering the trainability of individuals at different IQ levels, as indicated in the right portion of Figure 1. As suggested there, individuals below WPT 10 to 12 (IQ 80-83) are unlikely to benefit much from training in any formalized setting and will later need constant supervision using even simple tools. Even up to Wonderlic score 17 (IQ 95), workers tend to need explicit teaching of most of what they need to know, and they do not benefit much from "book learning" training. Better training technology might improve success rates for all groups, but it would not equalize them.

Employers understandably seek individuals with a greater capacity to learn independently and to work without close supervision, especially for more complex jobs. Indeed, the job descriptions of managerial, executive, and professional workers themselves suggest that high-IQ, self-trainable individuals are essential: that is, individuals who are better able to "learn much on their own" and from the "typical college format" (WPT 26-30, IQs over 110) and to "gather and synthesize information" and "infer information and conclusions from on-the-job situations" (WPT 28 and above, IQs over 116). This roughly 30\% of the working population above IQ 110 (25\% of the total adult population) would also be essential for training and supervising even the next lower third of the working population, which is "able to learn routines quickly" and with a "combination of written materials and actual job experience" (WPT 20-26, roughly IQ 100-113).

These conclusions concerning training potential, particularly at the lower levels, seem confirmed by the military's last half century of experience in training many millions of recruits. The military has periodically inducted especially large numbers of "marginal men" (percentiles 10-16, or WPT 10-12), either by necessity (World War II), social experiment (Secretary of Defense Robert McNamara's Project 100,000 in the late 1960 s), or accident (the ASVAB misnorming in the early 1980s). In each case, the military has documented the consequences of doing so (Laurence \& Ramsberger, 1991; Sticht et al., 1987; U.S. Department of the Army, 1965).

The major reports on these periodic influxes of low-aptitude men disagree on whether their performance levels warrant their enlistment in the military, but all agree that these men were very difficult and costly to train, could not learn certain specialties, and performed at a lower average level once on a job. Many such men had to be sent to newly created special units for remedial training or recycled one or more times through basic or technical training.

Sticht et al. (1987), who favor greater use of low-aptitude recruits ("cast-off 
youth"), are most explicit about the modifications in technical training they require and about "how difficult it is for the [military training] schools to train personnel of all aptitudes when slow learners may require two to five times more instructional time than more able learners" (p. 91). They report the conclusions of research on Project 100,000 men, which are that training for such individuals must be made as concrete, precise, structured, and job specific as possible. Subject matter must not be "decontextualized" (abstracted) from common, everyday experiences with which the men are familiar. Quoting Crawford (1962, p. 313), Sticht et al. (1987, p. 94) noted that successful training for low-aptitude men "in some cases . . . may be achieved if the training content is limited strictly to that which is relevant to a specific job, and no attempt is made to supply any underlying theory or more general instruction which might be useful to trainees of higher aptitude in fitting them for rapid advancement to positions of greater responsibility."

Laurence and Ramsberger (1991, pp. 146-147) were more skeptical about the future of low-aptitude men in the military:

The reluctance of the military to accept these men, let alone keep them, appears to be steadfast. Higher quality recruits are easier to train and retrain and show greater promise for moving up the ranks and leading others as noncommissioned officers. Defense downsizing as a result of the thawing of Cold War tensions further removes the likelihood of increasing, and may even reduce, reliance on low-aptitude youth . . . No one seems to want people of lowaptitude, at least for long.

\section{BUT WHY DOES $g$ MATTER?}

The foregoing examples of the practical importance of $g$ could be multiplied many times. The deeper question, however, is why does $g$ have such pervasive practical utility? For example, why is a higher level of $g$ a substantial advantage in carpentry, managing people, and navigating vehicles of all kinds? And, very importantly, why do those advantages vary in the ways they do? Why is $g$ more helpful in repairing trucks than in driving them for a living? Or more for doing well in school than staying out of trouble? For example, IQ correlates .5 to .7 with academic achievement (Jensen, 1980, p. 319), but only - .25 with delinquency (Gordon, 1986). What explains this pattern of results?

Also, can we presume that similar activities in other venues might be similarly affected by intelligence? For example, if differences in intelligence change the odds of effectively managing and motivating people on the job, do they also change the odds of successfully dealing with one's own children? If so, why, and how much?

The heart of the argument I develop here is this: For practical purposes, $g$ is the ability to deal with cognitive complexity - in particular, with complex informa- 
tion processing. All tasks in life involve some complexity, that is, some information processing. Life tasks, like job duties, vary greatly in their complexity ( $g$ loadedness). This means that the advantages of higher $g$ are large in some situations and small in others, but probably never zero.

\section{$\boldsymbol{g}$ Is the Ability to Deal With Complexity}

One of the liveliest areas of research on intelligence today concerns the brain "hardware" and information-processing "software" that compose intelligence. Researchers are just beginning to chart the neural basis of $g$. However, much is known about the behavioral manifestations of these underlying processes. It is these outward signs of what we commonly recognize as intelligence that are most relevant for understanding the role of $g$ in practical affairs.

Outward Manifestations of Intelligence. Although researchers disagree on how they define intelligence, there is virtual unanimity that it reflects the ability to reason, solve problems, think abstractly, and acquire knowledge (Snyderman \& Rothman, 1988, p. 56). Intelligence is not the amount of information people know, but their ability to recognize, acquire, organize, update, select, and apply it effectively. In educational contexts, these complex mental behaviors are referred to as higher order thinking skills.

Stated at a more molecular level, $g$ is the ability to mentally manipulate information- - "to fill a gap, turn something over in one's mind, make comparisons, transform the input to arrive at the output" (Jensen, 1981, p. 62).

Complexity: The "Active Ingredient" in Intelligence Tests. One reason that many people have trouble believing that intelligence is important is that the content of intelligence tests often seems remote from everyday demands (arranging blocks to copy specified designs, identifying the missing element in a picture, repeating digits in reverse order) or merely academic (vocabulary, arithmetic, analogies). They thus find it hard to conceive how the tests could possibly be measuring anything of benefit in daily affairs. However, the active ingredient in intelligence tests has nothing to do with their manifest content. This "indifference of the indicator" (Spearman, 1923) was one of the earliest discoveries in intelligence testing (see Jensen, 1980, chap. 5, for an extended discussion).

Instead, the active ingredient in test items seems to reside in their complexity. Any kind of item content-words, numbers, figures, pictures, symbols, blocks, mazes, and so on-can be used to create less to more g-loaded tests and test items. Differences in $g$ loading seem to arise from variations in items' cognitive complexity and thus the amount of mental manipulation they require. Digit span subtests provide a clear example of how complexity can be manipulated with identical content. In digits forward, individuals are asked to repeat a string of from two to nine digits (say, 6-2-1-8-3) that is presented orally at one digit per 
TABLE 3

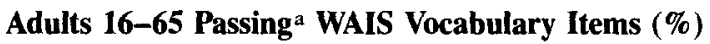

\begin{tabular}{|c|c|c|c|}
\hline Item & $\begin{array}{c}\text { Passing } \\
(\%)\end{array}$ & Item & $\begin{array}{c}\text { Passing } \\
(\%)\end{array}$ \\
\hline 1. Bed & 100 & 21. Terminate & 55 \\
\hline 2. Ship & 100 & 22. Obstruct & 58 \\
\hline 3. Penny & 100 & 23. Remorse & 51 \\
\hline 4. Winter & 99 & 24. Sanctuary & 49 \\
\hline 5. Repair & 98 & 25. Matchless & 41 \\
\hline 6. Breakfast & 99 & 26. Reluctant & 50 \\
\hline 7. Fabric & 92 & 27. Calamity & 50 \\
\hline 8. Slice & 94 & 28. Fortitude & 36 \\
\hline 9. Assemble & 90 & 29. Tranquil & 36 \\
\hline 10. Conceal & 87 & 30. Edifice & 22 \\
\hline 11. Enormous & 89 & 31. Compassion & 29 \\
\hline 12. Hasten & 87 & 32. Tangible & 30 \\
\hline 13. Sentence & 83 & 33. Perimeter & 26 \\
\hline 14. Regulate & 80 & 34. Audacious & 20 \\
\hline 15. Commence & 79 & 35. Ominous & 20 \\
\hline 16. Ponder & 64 & 36. Tirade & 17 \\
\hline 17. Cavern & 68 & 37. Encumber & 19 \\
\hline 18. Designate & 63 & 38. Plagiarize & 13 \\
\hline 19. Domestic & 65 & 39. Impale & 14 \\
\hline 20. Consume & 61 & 40. Travesty & 5 \\
\hline
\end{tabular}

second. In digits backward, the individual simply repeats the numbers in reverse order (in this case, 3-8-1-2-6). The one extra element in the second task (mentally "flipping" the list over) substantially increases its $g$ loading (Jensen \& Figueroa, 1975).

A little reflection also reveals how performance on even the most "academic" of tests, such as the Vocabulary subtest of the Wechsler Adult Intelligence Scale (WAIS; Wechsler, 1981), calls forth a highly general capacity for comprehending and manipulating information in the swirl of everyday life. We do not learn most words by memorization or direct instruction, but by inferring their meaningsand their fine nuances in meaning-from the way others use them. Learning vocabulary is largely a process of distinguishing and generalizing concepts.

Table 3 provides the passing rates in the 1955 standardization sample of the WAIS for its 40 vocabulary items (Matarazzo, 1972, p. 514). All individuals tested were able to provide at least a tolerable definition of concrete items such as bed, ship, and penny, but passing rates dropped quickly for more abstract and nuanced concepts such as slice (94\%), sentence $(83 \%)$, domestic $(65 \%)$, and obstruct $(58 \%)$. Only half of this nationally representative sample of 16 to 65 -year- 
TABLE 4

Adults 16-65 Passing a

WAIS Similarities Items $(\%)$

\begin{tabular}{ll}
\hline 1. Orange-Banana & 93 \\
2. Coat-Dress & 90 \\
3. Axe-Saw & 90 \\
4. Dog-Lion & 86 \\
5. North-West & 73 \\
6. Eye-Ear & 69 \\
7. Air-Water & 56 \\
8. Table-Chair & 55 \\
9. Egg-Seed & 46 \\
10. Poem-Statue & 38 \\
11. Wood-Alcohol & 21 \\
12. Praise-Punishment & 25 \\
13. Fly-Tree & 18 \\
\hline
\end{tabular}

aPassing includes getting at least partial credit.

Source Mataraz7o (1972., Table 4, p. 513) Reprinted by permission of Williams and Wilkins.

olds could define the words "remorse," "reluctant," and "calamity." Fewer than one in five knew the words "ominous" and "tirade," and only 5\% could provide even a partial definition of "travesty." None of these words is esoteric; anyone who has attended U.S. high schools or read national newspapers or magazines has surely encountered them. Vocabulary tests gauge the ease with which individuals have routinely caught on to new and more complex concepts they encounter in the general culture.

The Similarities subtest of the WAIS provides another example of how the manifest content of a test serves merely as a vehicle for creating differentially complex cognitive tasks. As shown in Table 4, all concepts in the subtest are well known; the most difficult test item uses the words "fly" and "tree." What the test requires is for people to state one way in which the two concepts (say, orangebanana or table-chair) are similar. It thus requires people to abstract key attributes or uses for each, compare those attributes, and then judge which ones are similar. Passing rates drop quickly as relations between the items become more abstract. Over $90 \%$ of the WAIS standardization sample could identify one pertinent similarity between oranges and bananas, but only $69 \%$ could do so for eyes and ears. Fewer than half succeeded in giving a similarity between egg and seed, and only one quarter produced one similarity between praise and punishment.

Seemingly more trivial items draw forth the same sort of graduated levels of abstraction and mental manipulation. Number series completion is an example. The Stanford-Binet Intelligence Scale (Thorndike, Hagen, \& Sattler, 1986), which is designed for school-aged children, includes number series like 3, 5, 7, 9, $11,13, \ldots, \ldots$ (an easy item); 3, 5, 6, 8, 9, _ _ (moderate); and 10, 9, 8, 9, 8, 
$7, \ldots, \ldots$ (difficult). One must discern the relations among succeeding numbers in order to complete the series. The relations become increasingly complex with successive items (in the foregoing examples, add 2 to each successive digit; add 3 to each successive set of two digits; subtract 1 from each successive set of three digits).

These sorts of mental processes - contrasting, abstracting, inferring, finding salient similarities and differences-are the building blocks of intelligence as manifested in reasoning, problem solving, and grasping new concepts with facility.

Conceptions of Task Complexity Highlight Demands for Information Processing. We lack systematic task analyses of IQ tests, partly because their development has traditionally been guided by empirical procedures (e.g., what discriminates best between individuals who are considered gifted, average, and retarded), rather than by theoretical considerations. However, the nature of objective task complexity has drawn attention in the fields of information processing, decision making, and goal setting (Campbell, 1988).

The terms used in different conceptions of task complexity connote a grounding in information-processing demands: multiple alternatives, inexact meansends, interrelated and conflicting subtasks, uncertain or unknown outcomes, information load and diversity, and rate of change. The various definitions tend to stress the number, variety, variability, ambiguity, and interrelatedness of information-not its substantive content--that must be processed to evaluate alternatives, make a judgment, and reach a decision.

Wood (1986), for example, discussed three dimensions of task complexity: component complexity (e.g., number of cues to attend to and integrate, redundancy of demands), coordinative complexity (e.g., timing or sequencing of tasks, length of sequences), and changes in cause-effect chains or means-ends relations).

This literature concerns itself with differences in tasks' information-processing demands, not with differences in individuals' ability to meet those demands. However, the task differences it identifies parallel the crucial task differences identified in IQ tests. This literature thus constitutes independent support for the inference that differences in IQ constitute differences in the capability to process diverse kinds of information in diverse situations.

\section{Complexity Is a Key Feature of the Workplace}

Life is replete with uncertainty, change, confusion, and misinformation, sometimes minor and at times massive. From birth to death, life continually requires us to master abstractions, solve problems, draw inferences, and make judgments on the basis of inadequate information. Such demands may be especially intense in school, but they hardly cease when one walks out the school door. A close look at job duties in the workplace shows why. 
Many organizations, civilian and military, turn to job analysis in order to understand how work might be better structured, what kinds of workers they should seek, and what sorts of training should be provided. Many inventories and standardized procedures are available for this purpose (Harvey, 1991). The Position Analysis Questionnaire (PAQ), for example, assesses almost 200 elements of work and work context (see Table 7) under about threc dozen categories (see Table 6). Data generated by such questionnaires have accumulated for many decades.

\section{The Major Distinction Among Jobs Is Their Cognitive Complexity (g Load-} edness). When job analysis data for any large set of jobs are factor analyzed, they always reveal the major distinction among jobs to be the mental complexity of the work they require workers to perform (e.g., Miller, Treiman, Cain, \& Roos, 1980). Arvey's (1986) job analysis is particularly informative in showing that job complexity is quintessentially a demand for $g$. His factor analysis of 65 job attributes for 140 jobs in the petrochemical industry showed that the major distinction among them was the degree of mental complexity they posed for workers. 'That first factor, accounting for $45 \%$ of the variance, was Judgment and Reasoning. Table 5 shows the job attributes loading highest on this factor. All are content-free mental tasks involving learning, problem solving, and information processingthe very essence of manifest intelligence. They are called forth when workers are confronted with novelty, change, uncertainty, unpredictability, and the need to spot and master new information and emerging problems.

Job Complexity Resides in Information-processing Demands. A factor analysis of a wider array of jobs, job attributes, and data sets (Gottfredson, 1984) illustrates in more detail the sources of this graduated complexity in overall job content. About $64 \%$ of the broad occupational titles (covering $86 \%$ of jobs) in the

TABLE 5

Job Analysis Items and Factor Loadings Associated With Judgment and Reasoning Factor Developed From 140 Petrochemical Jobs

\begin{tabular}{lc}
\hline Items & Factor Loading \\
\hline Deal with unexpected situations & .75 \\
Able to learn and recall job-related information & .71 \\
Able to reason and make judgments & .69 \\
Able to identify problem situations quickly & .69 \\
React swiftly when unexpected problems occur & .67 \\
Able to apply common sense to solve problems & .66 \\
Able to learn new procedures quickly & .66 \\
Alert and quick to understand things & .55 \\
Able to compare information from two or more & .49 \\
sources to reach a conclusion & \\
\hline
\end{tabular}

Source. Arvey (1986, p. 418). Reprinted by permission of Academic Press. 


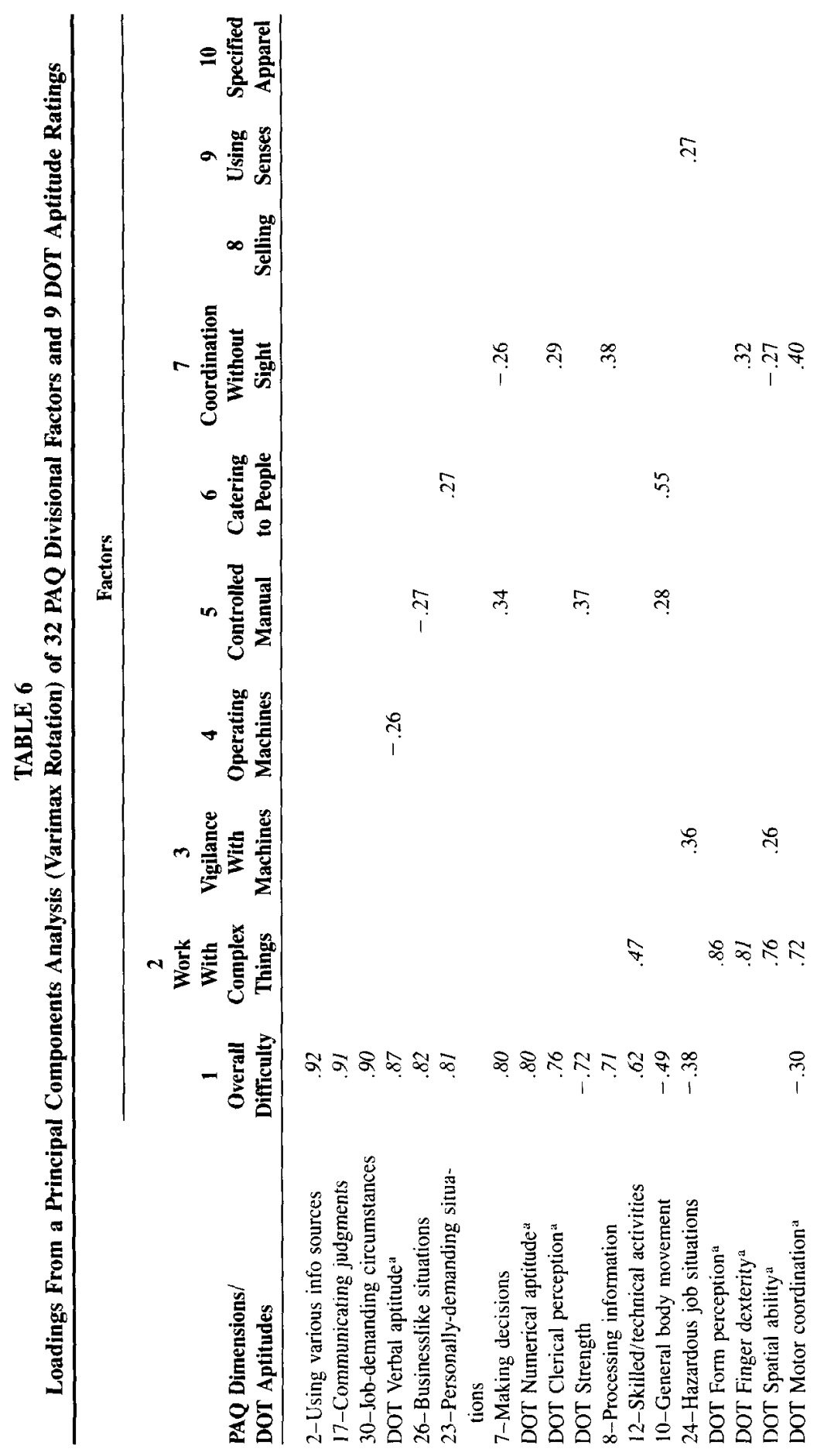




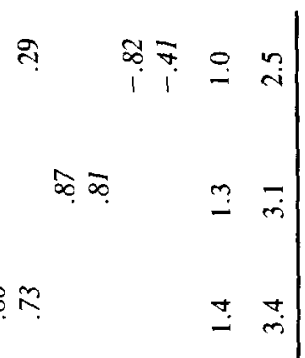

$$
\begin{aligned}
& \text { पू वे के } \\
& \text { สิ }
\end{aligned}
$$

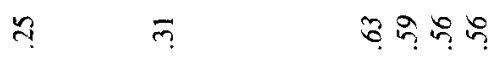

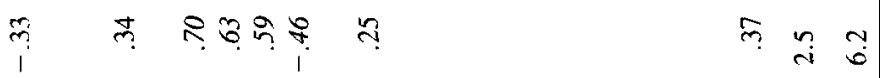

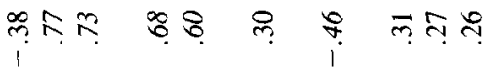

$$
\begin{aligned}
& 8 \%
\end{aligned}
$$

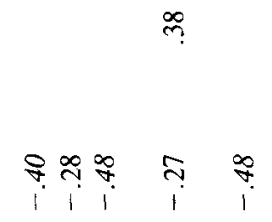

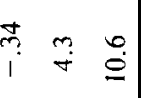

$$
\begin{aligned}
& \stackrel{\circ}{9} \\
& \approx
\end{aligned}
$$

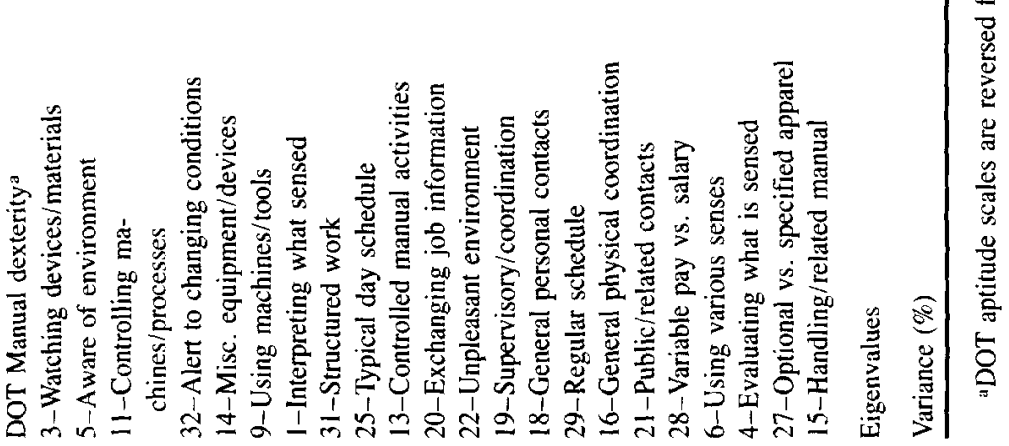




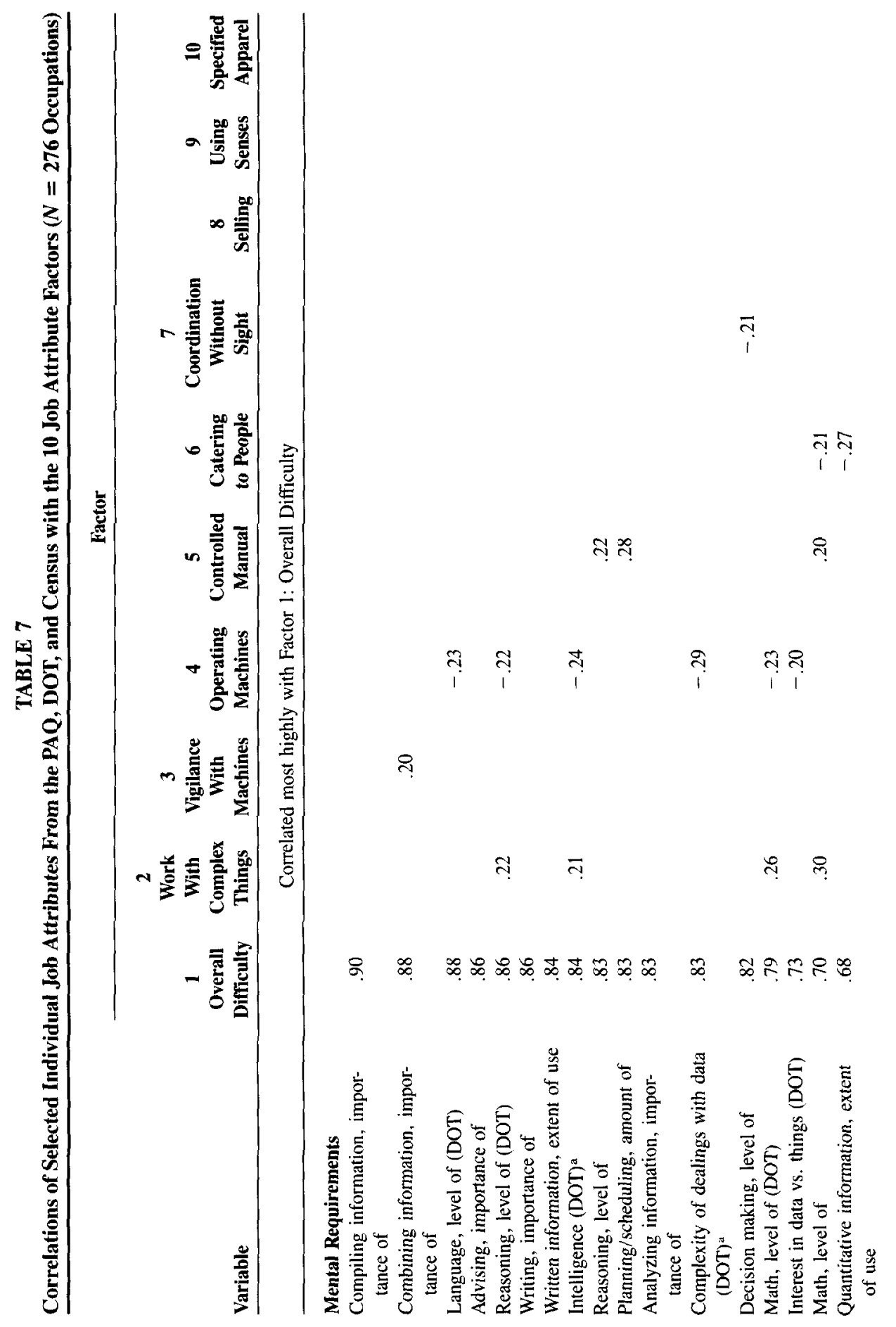


ิํ

$\overline{1}$

$\underset{\substack{\infty \\ \infty}}{\pi}$

กิ

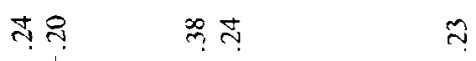

ฺุ

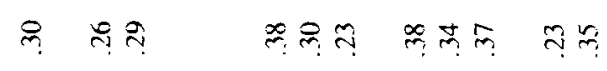

ชุกิ

ণุ̣

$\dddot{n}$

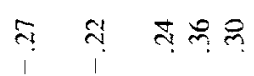

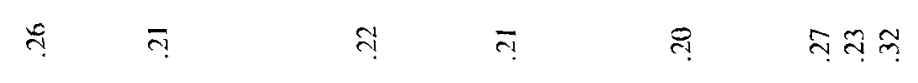

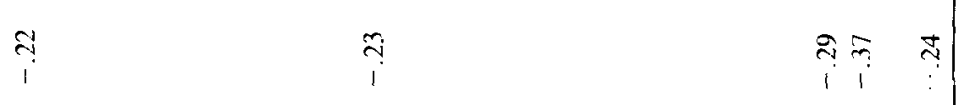

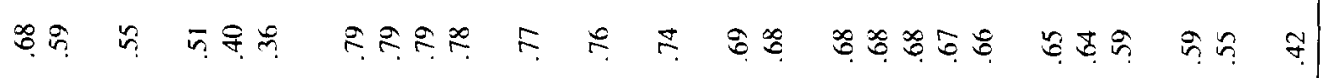

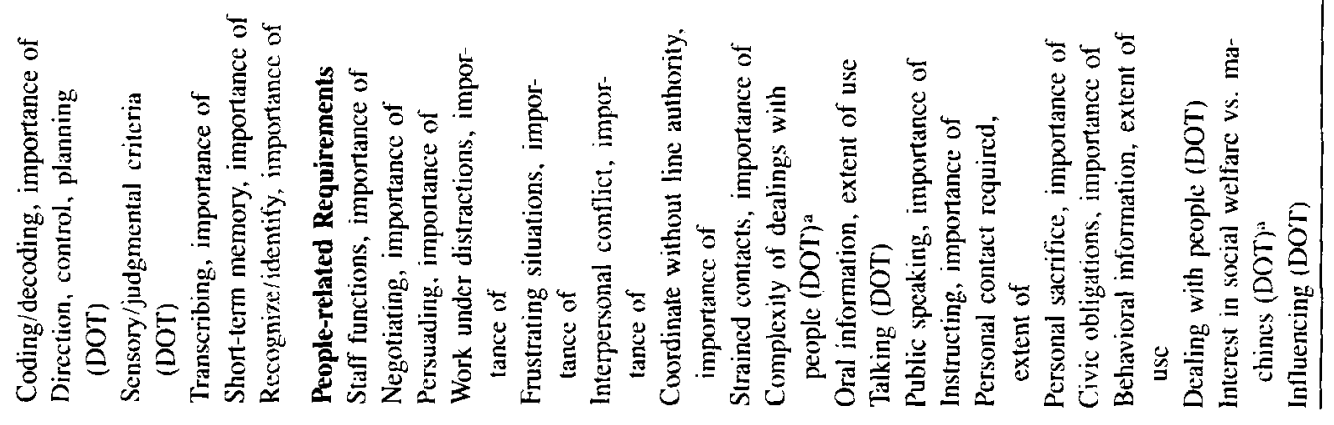




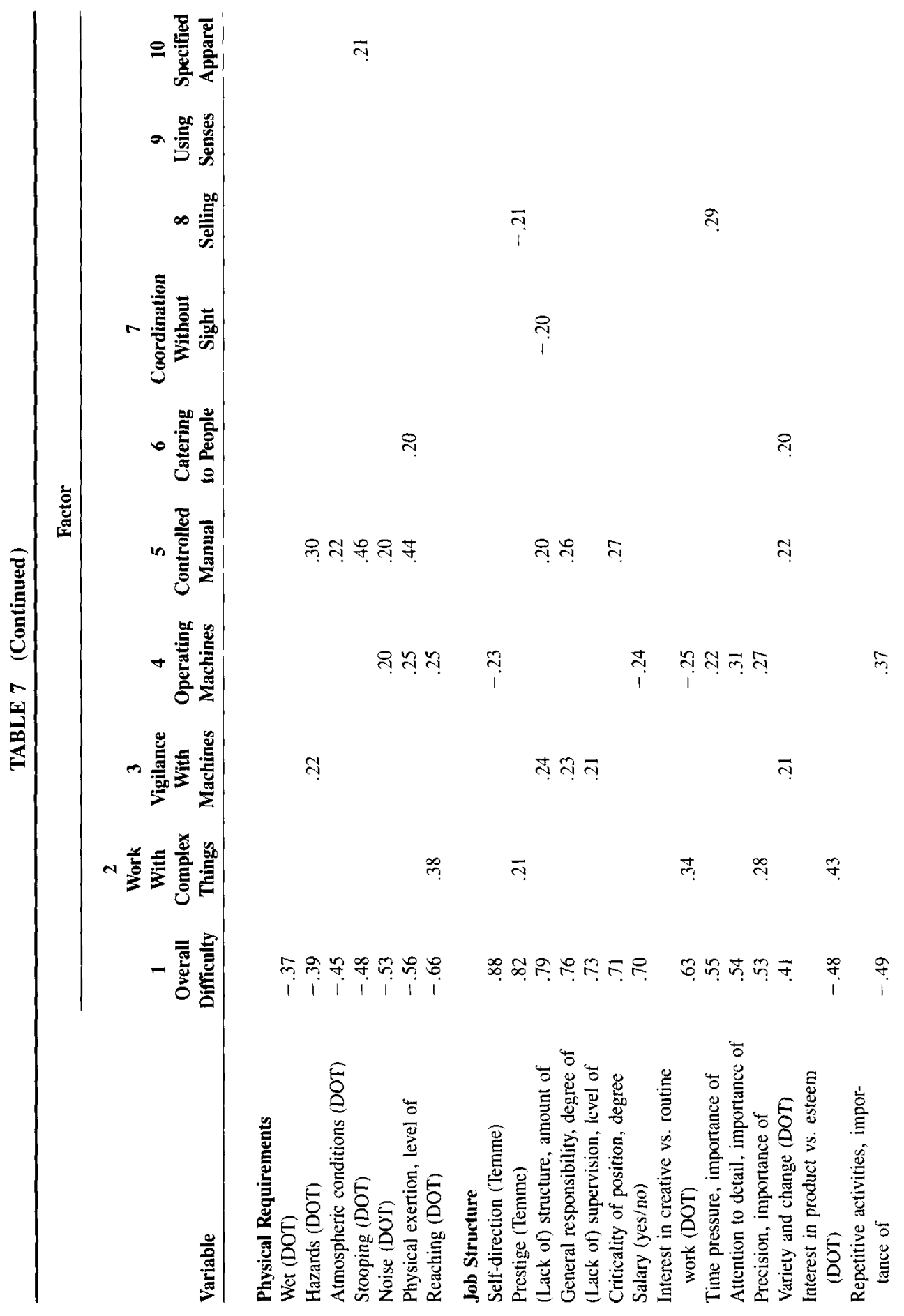




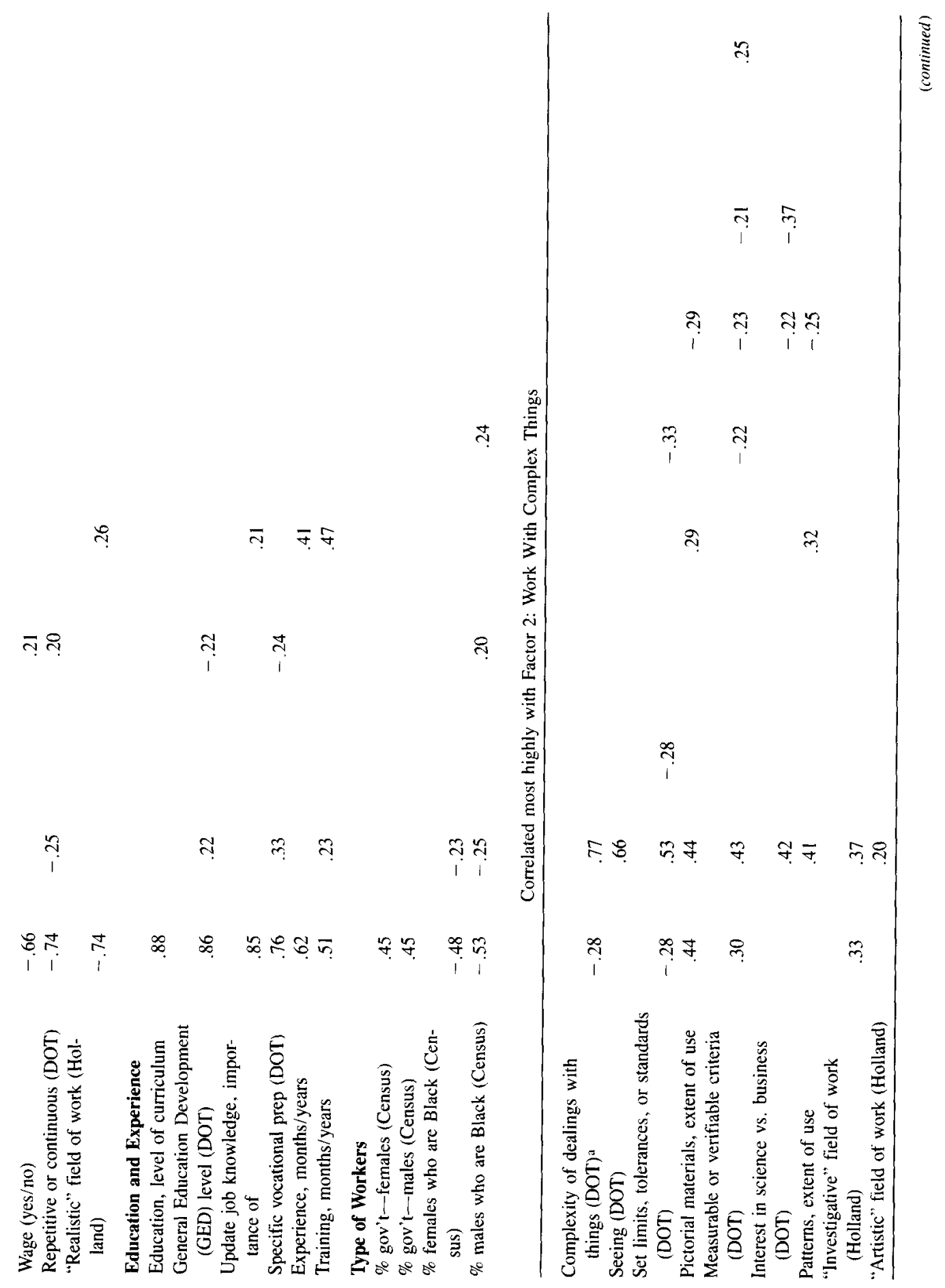




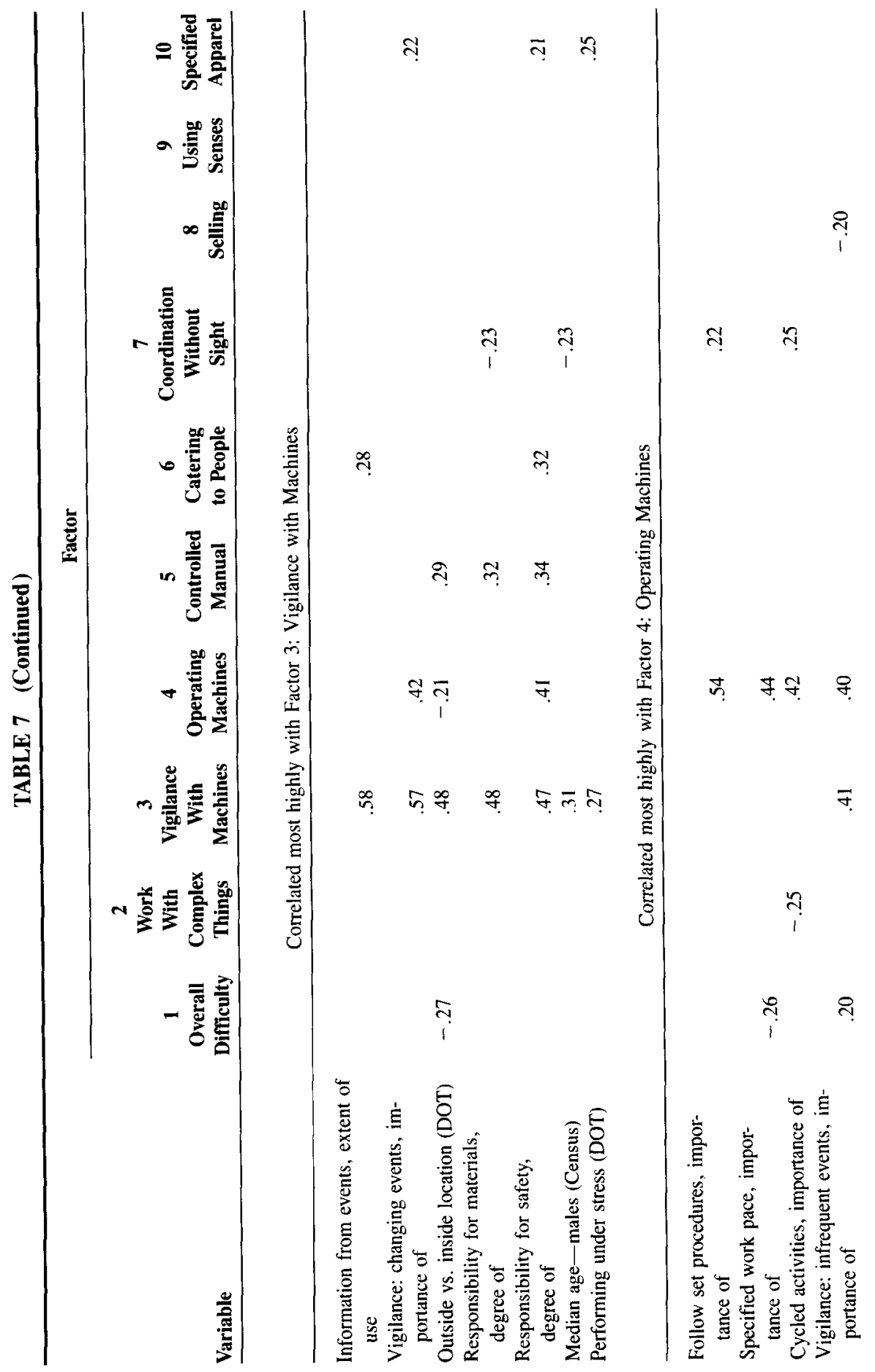




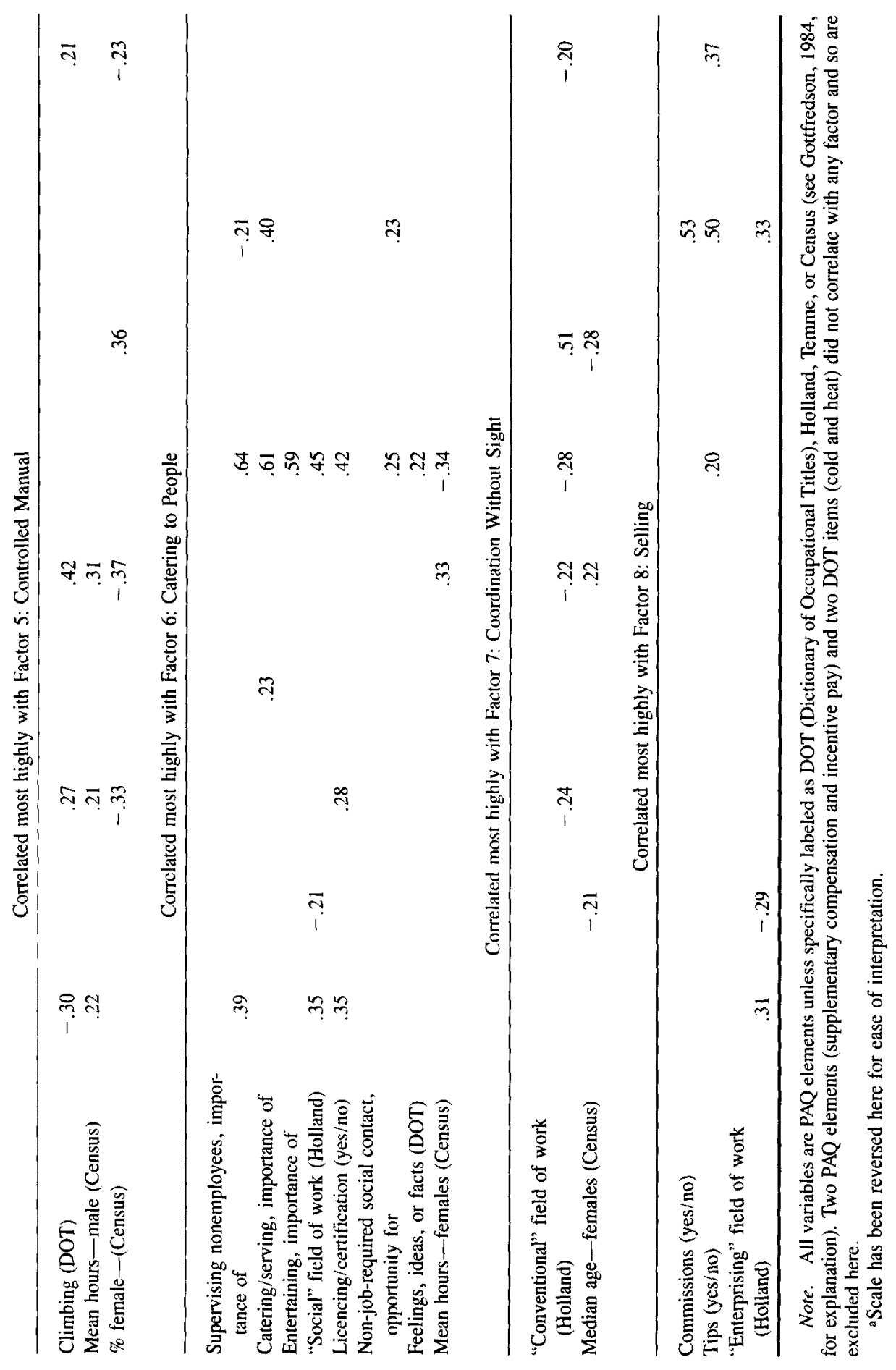


1970 census were characterized according to the major dimensions of job activities, aptitude requirements, and working conditions that had been documented in previous large studies of American jobs (Mecham, McCormick, \& Jeanneret, 1977; U.S. Department of Labor, 1970, 1977). A principal components factor analysis of these data yielded 10 orthogonal factors, shown in Table 6 . The first factor--labeled Overall Mental Difficulty--accounted for $26 \%$ of the total variance among these wide-ranging job attributes; the attributes loading most highly on this factor were the PAQ factors Using Various Information Sources, .92, and Communicating Judgments, .91. These results replicate Arvey's (1986) in suggesting that job complexity arises in large part from complexity of informationprocessing demands. They are also consistent with the finding that the validities of the GATB Intelligence Scale in predicting job performance rise (are themselves correlated) with PAQ ratings of the job's demands for decision making, $r=.37$; information processing, .24; and decision making/communication/general responsibility, .20 (Gutenberg et al., 1983).

The 10 factors in Table 6 were then correlated with more molecular job duties and work contexts (which had not been included in the factor analysis) to enhance their interpretation (see Table 7). These more elemental attributes included specific mental, people-related, and physical requirements; the structure, sequencing, and physical context of work performed; its prestige, criticality, and socialemotional demands; general education, training, and experience typically required; and selected demographic characteristics of job incumbents.

Complexity of Dealings with Data and Intelligence Level Required were equally and highly correlated, .84 and .83, with the Overall Mental Difficulty factor. High-level information-processing activities-compiling and combining information, planning, analyzing, reasoning, decision making, and advising-also correlated highly with that factor, .82 to .90 ; lower level mental processing activitiesidentifying, coding, transcribing, and remembering - correlated at a lower level, .36 to .68 . As might be expected, then, the simpler, less highly g-loaded information-processing activities were less highly correlated with this $g$ factor among jobs.

Jobs higher on this job complexity and intelligence factor also tend to be more critical to the organization, .71 . Other data show, in fact, that variance in performance levels among workers rises with job complexity. Hunter et al. (1990) found that the ratios of $S D$ in performance to mean performance were $19 \%, 32 \%$, and $48 \%$, respectively, in low-, medium-, and high-complexity civilian jobs. This means that the same differences in $g$ lead to bigger differences in performance in more complex jobs, because $g$ variance counts more heavily in those jobs.

Dealing With People Tends to Be Complex. The next pancl of Table 7 shows that Complexity of Dealings with People is fairly highly correlated, .68, with Overall Mental Difficulty. (It is correlated .48 with Complexity of Dealings With 
Data; Gottfredson, 1980.) The other people-related job requirements show how specific activities in dealing with people, like information-processing demands, also vary greatly in complexity. Negotiating, Persuading, and Staff (but not Line) Functions are all highly correlated, .79, with overall job complexity. Correlations are somewhat lower, .59 to .68 , for Extent of Personal Contact, Instructing, and Public Speaking, perhaps because they each encompass activities that themselves may range greatly in complexity. Supervising Nonemployees (such as children) is also reasonably complex, .39 (see Factor 6), as is Influencing Others, .42. Activities dealing with people almost always correlate more highly with the overall cognitive complexity factor than with the specifically people-related Factor 6 (Catering to People), which includes job elements pertaining primarily to entertainment and personal service.

Perhaps the most important conclusion to be drawn from these people-related ratings, however, is that dealing with people is always fairly complex. This should not be surprising, because other individuals are among the most complex, novel, changing, active, demanding, and unpredictable objects in our environments. Living and working with others is a complicated business.

Task Configuration Affects Complexity. The configuration of activities, as the task complexity literature suggests, can also increase job complexity. Task variety, change, ambiguity, and lack of supervision all contribute to complexity. Thus, we find that jobs high on the Overall Mental Difficulty factor tend to be unstructured, .79, and entail much self-direction, .88, and general responsibility, .76. They also tend to involve time pressure, .55; variety and change, .41; and attention to detail, .54; and to emphasize creative rather than routine activities, .63 . The more highly supervised, -.73 , repetitive, -.49 and -.74 , or physical, -.48 to -.66 , the job, the less cognitively complex it is.

\section{Complexity of Dealings With Things Is a Distinct and Secondary Fac-} tor. Complexity of dealings with things and with data are negatively correlated with each other, -.57 (Gottfredson, 1980), but the former is useful in distinguishing people-oriented versus things-oriented jobs at similar ranges of overall job complexity. Recall the two industrial job families that Hunter (1986) split off from other jobs of similar cognitive complexity. Hence, we see that Complexity of Dealings With Things defines (and is correlated .77 with) the second factor in Tables 6 and 7, labeled Complex Dealings With Things and Use of Patterns. As Table 6 indicates, jobs high on this factor (architects, physicians, draftsmen, painters, sculptors, pattern and model makers) require high perceptual (spatial, form perception) and psychomotor (finger dexterity and eye-hand coordination) aptitudes. This second factor (which accounts for $11.3 \%$ of the variance in the factor analysis) illustrates the point that other aptitudes, mental and physical, are 
functionally important in the world of work, but that they tend to be less important than $g$ overall.

High Levels of Education and Training Are Often Necessary But Not Sufficient in Highly Complex Jobs. Not surprisingly, jobs high in overall complexity require more education, .86 and .88 , training, .76 and .51 , and experience, .62and are viewed as the most prestigious, .82 . These correlations have sometimes been cited in support of the training hypothesis discussed earlier, namely, that sufficient training can render differences in $g$ moot.

However, prior training and experience in a job never fully prepare workers for all contingencies. This is especially so for complex jobs, partly because they require workers to continually update job knowledge, .85 . As already suggested, complex tasks often involve not only the appropriate application of old knowledge, but also the quick apprehension and use of new information in changing environments.

Education, training, experience, and the job knowledge to which they lead are all important aids in performing jobs well. This fact is aptly captured by discussions of the "practical intelligence" and "tacit knowledge" that is gained through experience (Jensen, 1993; Schmidt \& Hunter, 1993; Sternberg \& Wagner, 1993; Sternberg, Wagner, Williams, \& Horvath, 1995). Raw intelligence is not enough, as the path analyses of intelligence, knowledge, and performance discussed earlier suggest. However, knowledge is merely a tool that people apply with different degrees of competence to an unending array of new situations-some potentially critical (engine failure in flight, an injured or trapped child, plunging sales, corporate mergers) and others less so (novel questions or complaints from customers, comparison shopping, applying and interviewing for jobs, setting behavioral standards for one's adolescent children). As discussed earlier, the facility with which individuals accumulate these tools (trainability) and the competence with which they apply them (task proficiency) often depend heavily on $g$, especially in the absence of close supervision.

\section{Complex Job Duties Have Everyday Analogs}

Many of the duties that correlate highly with overall job complexity suffuse our lives: advising, planning, negotiating, persuading, supervising others, to name just a few. The job analysis tools used to analyze paid work could readily be adapted to analyze the nature of unpaid roles in life, such as parenting. One might ponder, for example, whether the most important elements of good parenting involve the duties associated with low complexity work such as driver, custodian, nurse's aide, messenger, and food service worker-or whether they are more like the duties of moderate to high complexity jobs such as teacher, counselor, dispatcher, police officer, and accountant. (See also Kohn \& Schooler's, 1983, pp. 340-344, analysis of the complexity of cooking, home repair, and other housework.) 


\section{COMPLEXITY IN THE NATIONAL ADULT LITERACY SURVEY: AN EXAMPLE OF THE FUNCTIONAL IMPORTANCE OF $g$}

The National Adult Literacy Survey (NALS) of 26,000 persons aged 16 and older (Kirsch, Jungeblut, Jenkins, \& Kolstad, 1993) is one in a series of national literacy assessments developed by the Educational Testing Service (ETS) for the U.S. Department of Education. It is a direct descendent, both conceptually and methodologically, of the National Assessment of Educational Progress (NAEP) studies of reading among school-aged children and literacy among adults aged 21 to 25 (Kirsch \& Jungeblut, 1990).

NALS, like its NAEP predecessors, is extremely valuable in understanding the complexity of everyday life and the advantages that higher $g$ provides. In particular, NALS provides estimates of the proportion of adults who are able to perform everyday tasks of different complexity levels. One criterion for including tasks in NALS is precisely that they have prima facie functional importance. Interpretability is further enhanced by presenting results on criterion-referenced scales, that is, in terms of the concrete levels of proficiency they represent.

\section{NALS Literacy Scales Are Highly $\boldsymbol{g}$ Loaded}

The NALS and NAEP literacy assessments are not IQ tests, nor were they intended to be. Four kinds of data suggest, however, that NALS is highly correlated with $g$. First, its design resembles that of an intelligence test in crucial ways: the intent was to measure "complex information-processing skills" that "go beyond simply decoding and comprehending text" by sampling a "broad range" of tasks that cover a variety of "universally relevant contexts and contents" and which can be "arrayed along a continuum" of difficulty (Campbell, Kirsch, \& Kolstad, 1992). Accordingly, demands for mere recall and school-based knowledge were minimized. Reports from ETS routinely interpret NALS and NAEP reading scores as measures of higher order thinking skills, reasoning, problem solving, and information processing (e.g., Kirsch, Jungeblut, \& Campbell, 1992; Mullis, Owen, \& Phillips, 1990; Venezky, Kaestle, \& Sum, 1987).

Second, factor analyses support the inference that NALS is highly correlated with verbal intelligence, if not $g$ itself. The three NALS scales (prose, document, and quantitative) correlate over .9 with each other in large national samples, and factor analyses of their items show that they measure primarily a single general factor (Baldwin, Kirsch, Rock, \& Yamamoto, 1995; Reder, 1995). This general literacy factor correlates .8 (in highly range-restricted samples, thus reducing the correlation) with the "academic G" factor of the General Educational Development (GED) exam. "Both assess skills that appear to represent verbal comprehension and reasoning, or the ability to understand, analyze, interpret, and evaluate written information and apply fundamental principles and concepts" (Baldwin et al., 1995, p. Xv.). 
As will be discussed further, the difficulty of NALS items stems from their complexity, not from their readability per se. Consistent with this, Sticht (1975) found that verbal comprehension test scores were no higher among military recruits when the test was administered to them orally rather than in written form.

Third, all tests of verbal ability are highly $g$ loaded, regardless of whether they are oral (individual tests like the WAIS) or written (group tests like the GATB and Wonderlic. For example, the Vocabulary subtest of the WAIS-R is correlated .85 and .81 with WAIS-R Verbal IQ and Full-Scale IQ (Wechsler, 1981, p. 46). WAIS Vocabulary and Verbal IQ are correlated .68 and .85 , respectively, with the GATB General Intelligence Scale (U.S. Department of Labor, 1970, pp. 32-34, 247-249). (See also Carroll's, 1993, chap. 5, three-stratum account of the relations among verbal ability, crystallized intelligence, and $g$ ).

Fourth, growth curves (ages 9-23) on the general NAEP reading scale resemble IQ growth curves in the general population, which has led some researchers to suggest that the NAEP reading scores represent the nation's "intelligence" (Ralph, Keller, \& Crouse, 1994) or "verbal intelligence" (Carroll, 1987, 1997).

\section{Difficulty Level of NALS Literacy Items Is Determined by Their Complexity}

Figure 2 shows the NALS prose, document, and quantitative scales. Specific test items are listed for different proficiency levels in order to anchor scores to readily interpreted behavior. (Proficiency here means having an $80 \%$ probability of correctly answering items at that level of difficulty.) The individual items are of inherent interest, and I will return to them shortly.

The three literacy scales order items in terms of their difficulty level. The pertinent question is, then, "What makes some NALS items more difficult than others?" ETS has devoted much effort to answering this question in order to enhance interpretability of its scales (e.g., Kirsch \& Jungeblut, 1990, chap. 3; Kirsch, Jungeblut, \& Mosenthal, 1994; Kirsch \& Mosenthal, 1990).

ETS analyses clearly reveal that difficulty within each literacy scale relates to the complexity of their items, not their substantive content. Beginning with a complex grammar for analyzing text, Kirsch and Mosenthal (1990) discovered that document difficulty arose primarily from "process complexity." They then developed three variables to measure such complexity in all three scales: type of match, plausibility of distractors, and type of information (or of calculation, in the case of the quantitative scale). Type of match refers to the literalness of the match between the information requested in the question and the information to be located in the text; more difficult items require readers to make an inference to perform successfully. Distracting (irrelevant) information enhances difficulty the more similar it is in nature or text location to the correct information. Type of information (in prose and document scales) refers to how abstract versus concrete the information is. Type of calculation (quantitative scale) refers to the number and difficulty of arithmetic operations that readers must discern and perform. 
These variables were found to account for $84 \%$ to $89 \%$ of the variance in task difficulty across the three scales: "The points on the scales at which major shifts in the processes and skills required for successful task performance were remarkably similar" across the three scales (Kirsch, Jungeblut, \& Mosenthal, 1994, p. 33). Despite large differences in manifest content, task difficulty in all three scales was rooted in the same "process complexity." In addition, a traditional measure of readability did not increase explained variance. Thus, complexity clearly lies in the information-processing demands of the tasks to be performed, not in the difficulty of the words and sentences describing the task to be performed.

Such findings are consistent with the literature on task complexity noted earlier, as well as with analyses of the information-processing demands of a different functional reading test (Kirsch \& Guthrie, 1980). Together, they support the inference that the NALS literacy scales measure primarily $g$.

\section{NALS Items Represent Practical, Everyday Skills}

A look at the items in Figure 2 reveals their general relevance to social life. These are not obscure skills or bits of knowledge whose value is limited to academic pursuits. They are skills needed to carry out routine transactions with banks, social welfare agencies, restaurants, the post office, and credit card agencies; to understand contrasting views on public issues (fuel efficiency, parental involvement in schools); and to comprehend the events of the day (sports stories, trends in oil exports) and one's personal options (welfare benefits, discount for early payment of bills, relative merits between two credit cards).

Table 8 shows the percentages of White adults who are proficient at each of the five levels on the three NALS scales. Generally about $4 \%$ reach the highest level. Level $5(376-500)$ signals an $80 \%$ probability, for example, of being able to summarize two ways that lawyers challenge prospective jurors (based on a passage discussing such practices) and to use a calculator to determine the total cost of carpet to cover a room (see Figure 2). Roughly another $20 \%$ of White adults reach Level 4 (326-375), where individuals can perform such tasks as restating an argument made in a lengthy news article and calculating the money needed to raise a child based on information stated in a news article.

A total of about one third of White adults reach Level 3 (276-325), but no higher, which includes capabilities for writing a brief letter explaining an error in a credit card bill and using a flight schedule to plan travel arrangements. Level 2 proficiency (226-275) includes locating an intersection on a street map, entering background information on an application for a social security card, and determining the price difference between two show tickets. This level is reached but not exceeded by about $25 \%$ of Whites. Finally, one out of seven White adults functions routinely no higher than Level 1 (less than 225), which is limited to $80 \%$ proficiency in skills like locating an expiration date on a driver's license and totaling a bank deposit. Individuals at Level 1 or 2 "are not likely to be able to perform the range of complex literacy tasks that the National Education Goals 
1

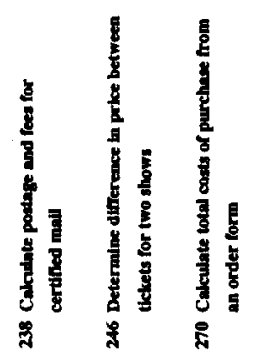

\|\|$\|$

11) $11 \|$

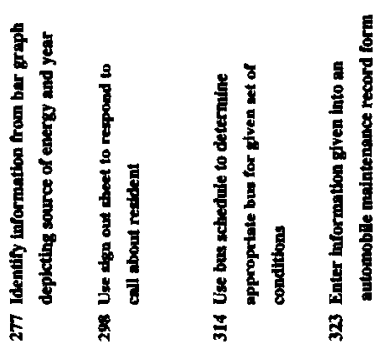

IIII

$\mid$

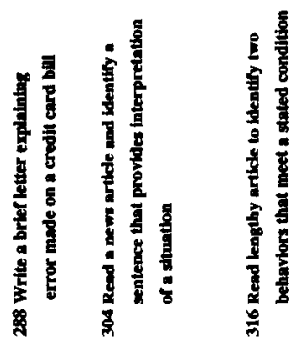




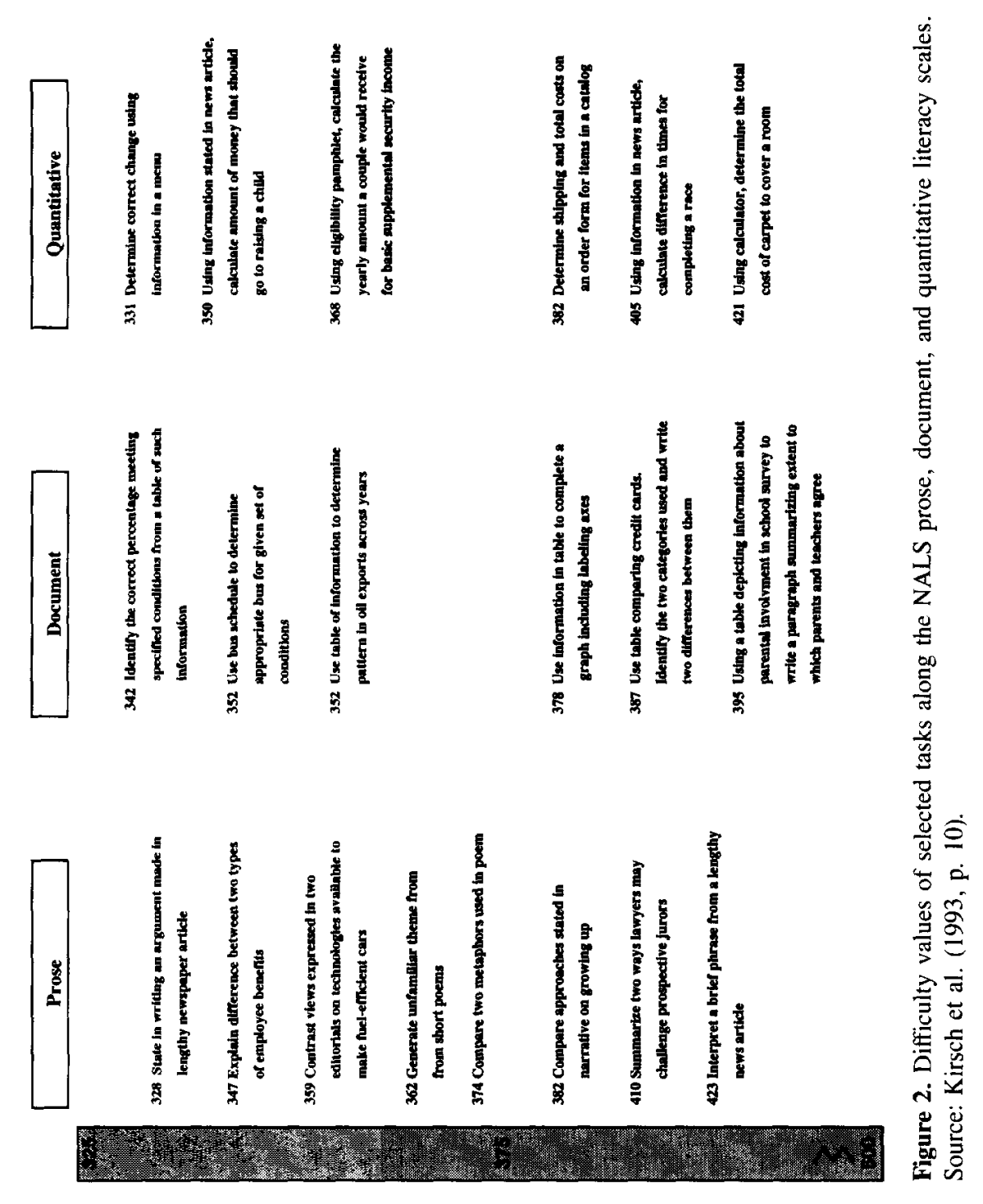


Panel considers important for competing successfully in a global economy and exercising fully the rights and responsibilities of citizenship" (Baldwin et al., 1995, p. 16).

To avoid confusion, it should be noted that no one item on the NALS, or any other mental test, is by itself a good measure of any ability. As is well known in psychometrics (see also Gordon, 1997), the fact that an individual passes or fails any single test item says little about that person's general intelligence level. What is crucial is the level of proficiency at which a person routinely functions on a wide variety of tasks. The point here is, thus, not that some people cannot do particular things like finding an intersection on a map (which presumably could be taught to most of them), but that some individuals routinely fail a high proportion of tasks at that complexity level (which is a much more difficult problem to remediate).

\section{NALS Scales Measure General Information-Processing Capability}

As just implied, although the NALS items represent skills that are valuable in themselves, they are merely samples from broad domains of such skill. As already suggested, scores on the NALS reflect people's more general ability (the latent trait) to master on a routine basis skills of different information-processing complexity: "Careful analysis of the range of tasks along each scale provides clear evidence of an ordered set of information-processing skills and strategies" (Kirsch et al., 1993, p. 9). It is therefore informative to describe the general informationprocessing capabilities represented by each of the five NALS proficiency levels.

Level I proficiency is characterized by identifying or matching single pieces of information or performing a single, simple, specified arithmetic operation (like addition) in contexts where there is little or no distracting information (e.g., see Kirsch et al., 1993, p. 11). As Table 8 indicates, about 14\% of White adults seem unable to function routinely at a higher level than this.

Level 2 tasks introduce distractors, more varied information, and the need for low-level inferences or to integrate two or more pieces of information. Information tends to be easily identifiable, despite the presence of distractors, and numeric operations are easily determined from the format of the material provided (say, an order form). About two in five White adults function routinely no higher than this level.

At Level 3 individuals are able to integrate multiple pieces of information from one or more documents, which themselves may be complex and contain much irrelevant information. However, the matches to be made between information and text tend to be literal or synonymous, and correct information is not located near incorrect information. Less than $60 \%$ of White adults reach or exceed this level of routine functioning. It takes the average person 14 years (from age 9 to 23) to progress from just above Level 1 to just above Level 3 (Carroll, 1987).

Multiple-feature matches, integration and synthesis of information from complex passages or documents, and use of multiple sequential operations are charac- 
TABLE 8

Whites Aged 16-65 at Five Levels of Proficiency on Three NALS Literacy Scales (\%)

\begin{tabular}{lcccc}
\hline $\begin{array}{l}\text { Proficiency level } \\
\text { (NALS scores) }\end{array}$ & $\begin{array}{c}\text { Scores in an } \\
\text { IQ metric }\end{array}$ & $\begin{array}{c}\text { Prose }^{\mathrm{c}} \\
\mathbf{( \% )}\end{array}$ & $\begin{array}{c}\text { Document } \\
(\%)\end{array}$ & $\begin{array}{c}\text { Quantitative }^{\mathrm{c}} \\
(\boldsymbol{\%})\end{array}$ \\
\hline $1(\leq 225)$ & $\leq 85$ & 14 & 16 & 14 \\
$2(226-275)$ & $86-97$ & 25 & 27 & 24 \\
$3(276-325)$ & $98-111$ & 36 & 34 & 35 \\
$4(326-375)$ & $112-127$ & 21 & 19 & 21 \\
$5(3 / 6-500)$ & $\geq 128$ & 4 & 3 & 5 \\
\hline
\end{tabular}

"Levels 1-4 on the NALS literacy scales correspond, respectively, to the "rudimentary" (score 150) plus "basic" (200), "intermediate" (250), "adept" (300), and "advanced" (350) NAEP reading levels for children and young adults. (There is no NAEP category corresponding to NALS Level 5.) Carroll (1987, p. 425) has estimated that the five NAEP levels correspond, respectively, to grade equivalents of 1.5 ("rudimentary"), 3.6 ("basic"), 7.2 ("intermediate"), end of Grade 12 ("adept"), and Grade 16 ("advanced").

'Estimated from cumulative normal distribution. To illustrate, about $14 \%$ of White adults are in Level 1 . The 14 th percentile corresponds to a $z$ score of about -1.08 on the normal curve. The White IQ mean is 101.4 and $S D$ is 14.7 (Reynolds, Chastain, Kaufman, \& McLean, 1987, p. 330). In that IQ distribution, a $z$ score of -1.08 corresponds to approximately IQ 85

'Source: Kirsch et al. (1993, Tables 1.1A-C).

teristic of Level 4. Level 5 further requires the application of specialized background knowledge, disembedding the features of a problem from text, and making high-level inferences from highly complex text with multiple distractors. Level 5 functioning is reached by only a small fraction of White adults-fewer than 1 in 25.

\section{NALS Skills Are Associated With Cumulative Life Outcomes}

These differences in proficiency level are clearly relevant in the workplace, where information-processing constitutes the key distinction among jobs today. Differences in NALS literacy thus portend different employment trajectories. And, indeed, the five levels of NALS literacy are associated with very different odds of economic well-being (see also Berlin \& Sum, 1988). Table 9 shows that the norm for Level 1 individuals is to be out of the labor force (52\%), whereas the norm for Level 5 individuals is to be at work in professional or managerial jobs (70\%). The former are 10 times more likely to be living in poverty (43\% vs. $4 \%$ ) and 17 times more likely to rely on food stamps (17\% vs. $1 \%)$. Median weekly wages are one third as high for Level 1 versus Level 5 individuals who are employed (\$240 vs. $\$ 650)$.

Each higher level of proficiency substantially improves the odds of economic well-being, generally halving the percentage living in poverty and doubling the percentage employed in the professions or management. As one ETS report (Kirsch \& Jungeblut, 1990, p. V-12) aptly sums up such consequences, "literacy is a currency not only in our schools, but in our society as well; and, as with money, it is better to have more literacy than less." 
TABLE 9

Economic Outcomes at Different Levels of NALS Literacy, Whites Aged 16-65 (\%)

\begin{tabular}{|c|c|c|c|c|c|c|c|}
\hline $\begin{array}{l}\text { Prose } \\
\text { Level }\end{array}$ & (Scores) & $\begin{array}{l}\text { Out of } \\
\text { Labor } \\
\text { Force }\end{array}$ & $\begin{array}{l}\text { Lives } \\
\text { in } \\
\text { Poverty }\end{array}$ & $\begin{array}{c}\text { Uses } \\
\text { Food } \\
\text { Stamps }\end{array}$ & $\begin{array}{l}\text { Employed } \\
\text { Full-time }\end{array}$ & $\begin{array}{l}\text { Median } \\
\text { Weekly } \\
\text { Wages }\end{array}$ & $\begin{array}{c}\text { Employed in } \\
\text { Professional } \\
\text { Managerial } \\
\text { Job }\end{array}$ \\
\hline 1 & $(\leq 225)$ & 52 & 43 & 17 & 30 & 240 & 5 \\
\hline 2 & $(226-275)$ & 35 & 23 & 13 & 43 & 281 & 12 \\
\hline 3 & $(276-325)$ & 25 & 12 & 6 & 54 & 339 & 23 \\
\hline 4 & $(326-375)$ & 17 & 8 & 3 & 64 & 465 & 46 \\
\hline 5 & $(376-500)$ & 11 & 4 & 1 & 72 & 650 & 70 \\
\hline
\end{tabular}

Source. Kirsch, Jungeblut, Jenkins, and Kolstad, 1993, Figures 2.5, 2.6, 2.7, 2.9, and 2.10.

\section{INFLUENCE OF INTELLIGENCE ON OVERALL LIFE OUTCOMES}

The effects of intelligence-like other psychological traits-are probabilistic, not deterministic. Higher intelligence improves the odds of success in school and work. It is an advantage, not a guarantee. Many other things matter.

However, the odds disfavor low-IQ people just about everywhere they turn. The differences in odds are relatively small in some aspects of life (law-abidingness), moderate in some (income), and large in others (educational, occupational attainment). But they are consistent. At a minimum (say, under conditions of simple tasks and equal prior knowledge), higher levels of intelligence act like the small percentage (2.7\%) favoring the house in roulette at Monte Carlo (Gordon, Lewis, \& Quigley, 1988, p. 430)-it yields enormous gains over the long run. Similarly, all of us make stupid mistakes from time to time, but higher intelligence helps protect us from accumulating a long, debilitating record of them (Gordon, 1997).

To mitigate unfavorable odds attributable to low IQ, an individual must have some equally pervasive compensatory advantage - family wealth, winning personality, enormous resolve, strength of character, an advocate or benefactor, and the like. Such compensatory advantages may frequently soften but probably never eliminate the cumulative impact of low IQ. Conversely, high IQ acts like a cushion against some of life's adverse circumstances, perhaps partly accounting for why some children are more resilient than others in the face of deprivation and abuse.

Figure 3 summarizes how overall life chances differ for individuals along different ranges of the IQ continuum. The five IQ segments shown there correspond to those analyzed by Herrnstein and Murray (1994). As Figure 3 shows, the percentages of the general population in these five ranges- $-5,20,50,20$, and 5 are approximately the same as for Whites specifically $(4,18,50,23$, and 5). 


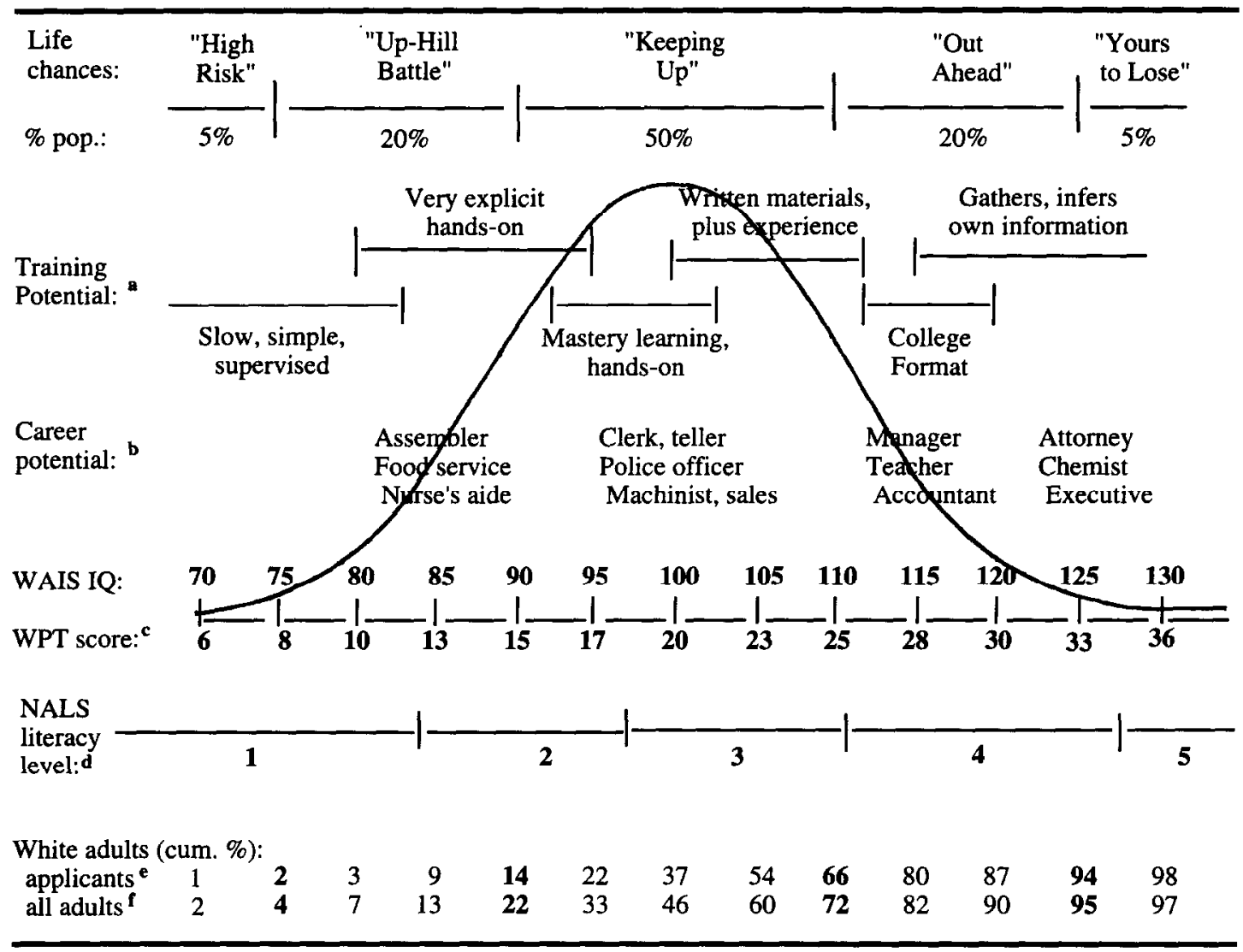

Figure 3. Overall life chances at different ranges of the IQ bell curve. ${ }^{\text {aWonderlic }}(1992$, p. 26).

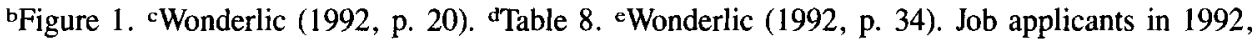
aged 16-72. 'Based on mean WAIS IQ for Whites of 101.4 and SD for Whites of 14.7 (Reynolds, Chastain, Kaufman, \& McLean, 1987, p. 330). Percentiles for IQ scores estimated using cumulative normal probability tables.

Recall that we are dealing here only with odds, not guarantees. Individuals may beat the odds for their IQ level if they have compensatory traits and advantages, or they may fall behind their IQ peers if they suffer other disadvantages by comparison. Individual outcomes vary enormously within any IQ range. What follows, then, is a portrait of the average for each group.

Life is difficult at the low end of the IQ bell curve (IQ 75 and below), as anthropologists have poignantly documented for mildly retarded adults (e.g., Edgerton, 1993, deinstitutionalized retarded adults; Gazaway, 1969, a low-IQ White Appalachian community; Koegel \& Edgerton, 1984, Black inner-city special education students as adults). This is the "high risk" zone: high risk of failing 
TABLE 10

Young White Adults With Particular Life Outcomes, by IQ Level (\%)

\begin{tabular}{|c|c|c|c|c|c|c|}
\hline Life Outcome & $\begin{array}{l}\leq 75 \\
\text { "Very } \\
\text { dull" }\end{array}$ & $\begin{array}{l}76-90 \\
\text { "Dull" }\end{array}$ & $\begin{array}{l}91-110 \\
\text { "Normal" }\end{array}$ & $\begin{array}{l}111-125 \\
\text { "Bright" }\end{array}$ & $\begin{array}{c}>125 \\
\text { "Very } \\
\text { Bright" }\end{array}$ & $\begin{array}{c}\text { Ratio } \\
\text { of Dull } \\
\text { to } \\
\text { Bright }\end{array}$ \\
\hline Married by age 30 & 72 & 81 & 81 & 72 & 67 & $8: 7$ \\
\hline $\begin{array}{l}\text { Out of labor force } 1+\mathrm{mo} / \mathrm{yr} \\
\text { (men) }\end{array}$ & 22 & 19 & 15 & 14 & 10 & $4: 3$ \\
\hline Unemployed $\mathrm{I}+\mathrm{mo} / \mathrm{yr}$ (men) & 12 & 10 & 7 & 7 & 2 & $3: 2$ \\
\hline Divorced in $5 \mathrm{yrs}$ & 21 & 22 & 23 & 15 & 9 & $3: 2$ \\
\hline $\begin{array}{l}\% \text { of children below IQ } 75 \\
\text { (mothers) }\end{array}$ & 39 & 17 & 6 & 7 & - & $2: 1$ \\
\hline Had illegitimate child (women) & 32 & 17 & 8 & 4 & 2 & $4: 1$ \\
\hline Lives in poverty & 30 & 16 & 6 & 3 & 2 & $5: 1$ \\
\hline $\begin{array}{l}\text { Went on welfare after first child } \\
\text { (women) }\end{array}$ & 55 & 21 & 12 & 4 & 1 & $5: 1$ \\
\hline $\begin{array}{l}\text { Ever incarcerated/doing time } \\
\text { (men) }\end{array}$ & 7 & 7 & 3 & 1 & 0 & $7: 1$ \\
\hline $\begin{array}{l}\text { Chronic welfare recipient } \\
\text { (mothers) }\end{array}$ & 31 & 17 & 8 & 2 & 0 & $8: 1$ \\
\hline High school dropout & 55 & 35 & 6 & 0.4 & 0 & $88: 1$ \\
\hline
\end{tabular}

Source. Herrnstein and Murray, 1994, pp. (respectively) 171, 158, 163, 174, 230, 180, 132, 194, 247-248, $194,146$.

elementary school, being unmasked as incompetent in daily affairs (making change, reading a letter, filling out a job application, understanding doctors' instructions, monitoring one's young children), being cheated by merchants and exploited by friends and relatives, remaining unemployed, dependent, and socially isolated, and "consistently fail[ing] to understand certain important aspects of the world in which they live, and so regularly find[ing] themselves unable to cope with some demands of this world" (Edgerton, 1993, p. 222). Many eventually lead satisfying lives, but only with the help of a benefactor or strong social support network or only after a long struggle to find a self-affirming social niche. Very low-IQ individuals who live independently tend to live volatile, unpredictable lives, because they lack the stabilizing resources that greater competence brings: networks of concerned and capable friends or relatives, job security, savings, credit, health insurance, marketable skills (Edgerton, 1993, p. 198).

Survey data show that most young White adults in this range marry, work, and have children (Herrnstein \& Murray, 1994), but, as Table 10 shows, they are nonetheless at great risk of living in poverty $(30 \%)$, bearing children out of wedlock (32\%), and becoming chronic welfare dependents (31\%). As noted before, they are prohibited from enlisting in the military, and no civilian jobs routinely recruit them. They are increasingly vulnerable - and unemployable - as unskilled jobs disappear. 
Fortunately, because of regression to the mean, their children will tend to be brighter than they are, but 4 in 10 still have IQs below 75 (Table 10). Thus, although these adults' child-rearing capabilities are surely below average, their parenting challenges tend to be greater. As a group, these are highly vulnerable individuals and families, especially in each other's company.

Life is easier and more stable, but still an "uphill battle" for the next $20 \%$ of the bell curve (IQ 76-90). More training and job opportunities are within reach cognitively, but they tend to be the least desirable and least remunerative: production workers, welders, machine operators, custodians, and food service workers. The work is atypically dangerous, physically difficult, and/or performed in unpleasant circumstances (Table 7). Individuals at this level tend not to be competitive for higher level work, in part because its training is relatively difficult for them. Over half are what the military used to call marginal men for purposes of military service (below the 16th percentile). At this IQ level, fewer than half the high school graduates and none of the dropouts meet the military's minimum AFQT enlistment standards. As seen in Table 10 , rates of poverty $(16 \%)$ and social pathology among young White adults at this IQ level are still substantial (35\% drop out of school; $17 \%$ of mothers are chronic welfare recipients), which suggests that socioeconomic progress and stability remain tenuous for adults of below-average intelligence.

The middle $50 \%$ of the bell curve (IQ $91-110$ ) - the average person-is readily trained for the bulk of jobs in society: clerks and secretaries, skilled trades and protective service workers, dispatchers, insurance sales representatives, and other midlevel work. All high school graduates and most of the dropouts in this range meet the military's minimum mental ability enlistment standards. Life is more secure and rates of poverty and pathology are much lower than for individuals in the "battling uphill" range (IQ 76-90): as seen in Table 10 for young White adults, dropout rates are, by comparison with that lower IQ group, cut by 6 (from $35 \%$ to $6 \%$ ) and poverty, illegitimacy, and chronic welfare dependence all fall by half (from about $16 \%-17 \%$ to $6 \%-8 \%$ ).

The rates of distress for this middle-IQ group are still at least several multiples higher, however, than those for the next higher IQ range (IQ 111-125): two times higher for poverty and illegitimacy, three to four times higher for welfare dependence and incarceration, and 15 times higher for dropping out of high school. Individuals in this vast middle range of the population function at either NALS literacy Levels 2 (the NAEP “intermediate" level) or 3 (NAEP "adept" level). Carroll (1987) has estimated that reading materials at these two levels include simple popular magazines ("intermediate") and most newspaper stories and popular novels ("adept").

The next higher $20 \%$ of the IQ distribution (IQ 111-125, or the 75th-95th percentiles) is "out ahead" as far as life chances go. Most occupations are within reach cognitively, because these individuals learn complex material fairly easily and independently. Their odds are quite good for being able to enter graduate or 
professional school and for finding work in management or the professions. None would be barred from even the most selective occupational specialties in the military on the basis of inadequate $g$ (Eitelberg, 1988, pp. 132-135). Only $2 \%$ to $3 \%$ of young White adults in this IQ range live in poverty or go on welfare.

As shown in the last column of Table 10 , it is far better to be somewhat above than somewhat below average in IQ (i.e., "bright" or "out ahead" rather than "dull" or "battling uphill"). The degree of advantage differs by the outcome in question. The percentages of "dull" White men who are unemployed (or divorced) is not much greater than those for "bright" White men (3:2). However, the percentages diverge increasingly for bearing an illegitimate child (4:1), living in poverty or women going on welfare after the birth of the first child (5:1), men being incarcerated $(7: 1)$, mothers becoming a chronic welfare recipient $(8: 1)$, or dropping out of high school $(88: 1)$. The odds diverge most for the outcomes generally considered most serious.

Individuals in the "out ahead" IQ range read at NALS Level 4 (NAEP "advanced"), which gives them access to reading material such as Time magazine, editorials in newspapers such as the New York Times, articles in Scientific American, and novels by Joseph Conrad and Thomas Mann (Carroll, 1987). Even these IQ-advantaged individuals, however, may have trouble with legal documents and tax instructions, because they are written "considerably above the 350 [NAEP "advanced"] point on the Reading Proficiency scale" (Carroll, 1987, p. 425).

For the top $5 \%$ of the population (over IQ 125), success is really "yours to lose." These people meet the minimum intelligence requirements of all occupations, are highly sought after for their extreme trainability, and have a relatively easy time with the normal cognitive demands of life. Their jobs are often high pressure, emotionally draining, and socially demanding (Table 7), but these jobs are prestigious and generally pay well. Although very high IQ individuals share many of the vicissitudes of life, such as divorce, illness, and occasional unemployment, they rarely become trapped in poverty or social pathology. They may be saints or sinners, healthy or unhealthy, content or emotionally troubled. They may or may not work hard and apply their talents to get ahead, and some will fail miserably. But their lot in life and their prospects for living comfortably are comparatively rosy (e.g., see follow-ups of gifted students, Subotnik \& Arnold, 1994).

There are, of course, multiple causes of different social and economic outcomes in life. However, $g$ seems to be at the center of the causal nexus for many. Indeed, $g$ is more important than social class background in predicting whether White adults obtain college degrees, live in poverty, are unemployed, go on welfare temporarily, divorce, bear children out of wedlock, and commit crimes (Herrnstein \& Murray, 1994, chap. 5-11).

There are many other valued human traits besides $g$ (e.g., see Gardner, 1983, on "multiple intelligences"), but none seems to affect individuals' life chances so systematically and so powerfully in modern life as does $g$. To the extent that one is 
concerned about inequality in life chances, one must be concerned about differences in $g$.

\section{THE FUTURE}

Complexity enriches social and cultural life, but it also risks leaving some individuals behind. Democracies are especially troubled by the social inequalities created by increasing cognitive complexity (Gottfredson, 1996). The bad news is that this challenge is increasing. The good news is that there are more effective approaches to meeting it.

\section{The Increasing Challenge}

Trends in Complexity. Society has become more complex-and $g$ loaded-as we have entered the information age and postindustrial economy. Major reports on the U.S. schools, workforce, and economy (e.g., Johnston \& Packer, 1987; National Commission on Excellence in Education, 1983) routinely argue, in particular, that the complexity of work is rising.

Where the old industrial economy rewarded mass production of standardized products for large markets, the new postindustrial economy rewards the timely customization and delivery of high-quality, convenient products for increasingly specialized markets. Where the old economy broke work into narrow, routinized, and closely supervised tasks, the new economy increasingly requires workers to work in cross-functional tcams, gather information, make decisions, and undertake diverse, changing, and challenging sets of tasks in a fast-changing and dynamic global market. Accordingly, organizations are "flatter" (have fewer hierarchical levels), and increasing numbers of jobs require high-level cognitive and interpersonal skills (Carnevale, 1991; Cascio, 1995; Hunt, 1995; Secretary's Commission on Achieving Necessary Skills, 1991).

Such reports emphasize that the new workplace puts a premium on higher order thinking, learning, and information-processing skills (see especially Hunt, 1995) - in other words, on intelligence. Gone are the many simple farm and factory jobs where a strong back and willing disposition were sufficient to sustain a respected livelihood, regardless of IQ. Fading too is the need for highly developed perceptual-motor skills, which were once critical for operating and monitoring machines, as technology advances (Hunt, 1995, chap. 6).

Daily life also seems to have become considerably more complex (cf. Herrnstein \& Murray, 1994, chap. 22). For instance, we now have a largely moneyless economy-checkbooks, credit cards, and charge accounts-that requires more abstract thought, foresight, and complex management. More self-service, whether in banks or hardware stores, throws individuals back onto their own capabilities. We struggle today with a truly vast array of continually evolving complexities: the changing welter of social services across diverse, large bureaucracies; increasing options for health insurance, cable, and phone service; the 
steady flow of debate over health hazards in our food and environment; the maze of transportation systems and schedules; the mushrooming array of over-the-counter medicines in the typical drugstore; new technologies (computers) and forms of communication (cyberspace) for home as well as office.

Brighter individuals, families, and communities will be better able to capitalize on the new opportunities this increased complexity brings. The least bright will use them less effectively, if at all, and so fail to reap in comparable measure any benefits they offer. There is evidence that increasing proportions of individuals with below-average IQs are having trouble adapting to our increasingly complex modern life (Granat \& Granat, 1978) and that social inequality along IQ lines is increasing (Herrnstein \& Murray, 1994).

Trends in National Intelligence. The trends in national intelligence are unclear. There is evidence of increases in average intelligence test scores across the developed world, although their source is as yet a matter of speculation. There is also, however, evidence of dysgenic trends in birthrates (see Herrnstein \& Murray, 1994, for discussions of both issues).

For our purposes it is sufficient to point out that, whatever the trends, there is widely perceived to be a growing gap between the information-processing skills the nation needs and the skills Americans possess. That is the urgent message of virtually all of the aforementioned education and training reform reports. Those reports trace falling levels of job capability to the disproportionate growth of the "disadvantaged" sectors of U.S. society. They note, quite correctly, that the future of these groups and of the nation as a whole is unsettling unless the growing skills gap can be narrowed.

Perhaps more importantly, it must be recognized that an aggregate rise in intelligence, should it exist, does not necessarily imply any equalization of intelligence levels in the population. Dispersion in $g$ - the IQ bell curve - is a stable feature of all human societies. Schools and other institutions may widen or narrow those differences somewhat (Jencks et al., 1972), but nothing seems likely ever to eliminate them.

\section{New Directions for Social Policy}

It is surely true that most students can learn more than they now do. Most have untapped strengths, mental and otherwise. There is much to the lament that U.S. educational standards are low. Higher standards, better instruction, and more incentives for learning might indeed work wonders in better preparing students for productive work. However, they will not transform slow, concrete learners into fast, abstract thinkers capable of processing large, complex, and ever-shifting bodies of information.

Societies can, however, develop and use their members' different capabilities in more effective ways. Indeed, a society's collective welfare requires that it make 
good use of its most talented members but also find productive roles for its least talented. Much less is known about accomplishing the latter than the former, but knowledge about the complexity of work reveals new opportunities. To begin with, it suggests that social policy might attend more in the near term to manipulating the environmental complexity individuals face than to changing their intelligence levels.

Reduce Complexity, Where Feasible and Appropriate. Radically simplifying education, occupations, and social life across the board is obviously neither feasible nor wise. However, audits of complexity might reveal unnecessary complexity in particular settings. The military, for example, lowered the reading levels of its technical manuals when it discovered that these manuals often required reading skills many grades levels above the average recruit (Sticht, 1975). Medical workers have likewise become acutely aware that routine instructions and requests are often incomprehensible to low-literacy patients (Williams et al., 1995). Public health education programs might also be scrutinized for the levels of $g$ they effectively require of their intended audiences. A sophisticated, subtle AIDS awareness campaign, for example, is probably least accessible to the populations who need it most.

Task complexity can be reduced somewhat in particular jobs or for particular workers, for example, by providing closer supervision or assigning the more g-loaded tasks to other jobs or workers. Practiced consistently or on a large scale, such job simplification would eventually lower those jobs' pay scales. Nonetheless, it is worth considering how to fashion or retain productive jobs that are simple enough for low-IQ individuals.

Focus on Specific Training, Not Broad Education, When Time and Ability to Learn Are Limited. The key problem with low IQ is not that it necessarily renders people incapable of mastering moderately complex tasks, because there is some evidence that, with extensive time and focused practice, lower IQ individuals can master tasks normally associated with higher IQ (e.g., Ceci \& Liker, 1986 , on racetrack handicapping). Rather, the practical problem is that it takes less intelligent individuals longer to master tasks (Carroll, 1997; Jensen, 1989b), especially more complex ones. Learning at a slower rate means that such individuals often master far fewer tasks than their brighter compatriots, even when those tasks are not particularly complex.

Optimizing learning among lower IQ individuals therefore requires narrowing the material to be learned to the most essential and then presenting it in the most accessible way. With regard to content, this means emphasizing the basics. With regard to method, this means more concrete, experience-based (less $g$-dependent) learning that ties in with what individuals already know. As already noted, this is exactly what the military has done in attempting to cope with low-aptitude re- 
cruits. It does not try to turn them into thinkers with highly transferable capabilities, but into doers with very particular, highly job-specific skills.

As the military experience also illustrates, however, what is good pedagogy for the low-aptitude learner may be inappropriate for the high-aptitude person. Research in educational settings finds that low- $g$ learners require highly structured, detailed, concrete, and "contextualized" instruction that omits no intermediate steps, but that such "complete" instruction is actually dysfunctional for high-g individuals. The latter easily fill gaps in instruction on their own and benefit most from abstract, self-directed, incomplete instruction that allows them to assemble new knowledge and reassemble old knowledge in idiosyncratic ways (Snow \& Lohman, 1984).

Enhance Important But Less g-loaded Competencies. A recurring theme in studies of very low-IQ individuals is that their social adaptation is greatly enhanced by certain personality traits, particularly persistence and a willingness to adhere to their community's rules and norms. These findings dovetail with recent research in industrial-organizational psychology on the importance of workers' "organizational citizenship behavior" (OCB; Organ, 1994) and "contextual performance" (Cascio, 1995). These are the more discretionary, pro-social job behaviors that contribute to a group's or organization's effectiveness, but which are more constrained by workers' intent than ability - for example, helping others with heavy workloads and always being punctual. "Altruism" and "conscientiousness" seem to be the most important, but "courtesy," "sportsmanship," and "civic virtue" are other documented OCB factors (Organ, 1994). Supervisors and peers highly value these "will do" as distinct from "can do" attributes of workers.

It is not clear how malleable OCB dispositions are, but they are largely independent of $g$. High conscientiousness is no panacea for low IQ, but it does seem to improve absolute and relative functioning and to garner the individual additional social support. Low conscientiousness and low IQ are surely a disastrous combination. Individuals with below-average IQs might therefore benefit as much from efforts to enhance their citizenship behavior as their intellectual skills. Such, in fact, may be the major benefit of Head Start.

Differences in intelligence matter. For members of the cognitive elite to maintain otherwise is like the rich arguing that money does not matter. Differences in $g$ affect the lives of individuals and families. They help shape the social order and limit our ability to reshape it (Gottfredson, 1985, 1986b; Gottfredson \& Sharf, 1988).

Much social policy has long been based on the false presumption that there exist no stubborn or consequential differences in mental capability. Worse than merely fruitless, such policy has produced one predictable failure and side effect after another, breeding widespread cynicism and recrimination. Educators routinely overpromise and schools, accordingly, consistently disappoint. Welfare reformers do not take seriously the possibility that today's labor market cannot or 
will not utilize all low-IQ individuals, no matter how motivated they may be. Civil rights advocates resolutely ignore the possibility that a distressingly high proportion of poor Black youth may be more disadvantaged today by low IQ than by racial discrimination, and thus that they will realize few if any benefits (unlike their more able brethren) from ever-more aggressive affirmative action. Virtually cveryone is capable of living productive, fulfilling lives in which they contribute to the general welfare of their communities. However, protecting and enhancing that potential requires us to appreciate its greater vulnerability to disruption among lower IQ individuals.

The $g$-related challenges in fashioning a simultaneously fair, compassionate, and economically competitive society are far greater than we might wish. However, those challenges can be more effectively met if social scientists and policy analysts begin to take their true measure. Taking $g$ seriously is a necessary first step.

Acknowledgment: I wish to thank the following people for their helpful comments: Jan H. Blits, John B. Carroll, Robert A. Gordon, Lloyd G. Humphreys, Arthur R. Jensen, Eliot Long, David Lubinski, Malcolm J. Ree, Frank L. Schmidt, James C. Sharf, and Julian C. Stanley.

\section{REFERENCES}

Ackerman, P.L. (1987). Individual differences in skill learning: An integration of psychometric and information processing perspectives. Psychological Bulletin, 102, 3-27.

Arvey, R.D. (1986). General ability in employment: A discussion. Journal of Vocational Behavior, $29,415-420$.

Baldwin, J., Kirsch, I.S., Rock, D., \& Yamamoto, K. (1995). The literacy proficiencies of GED examinees: Results from the GED-NALS comparison study. Washington, DC: American Council on Education and Educational Testing.

Barrick, M.R., \& Mount, M.K. (1991). The big five personality dimensions and job performance: A meta-analysis. Personnel Psychology, 44, 1-26.

Berlin, G., \& Sum, A. (1988). Toward a more perfect union: Basic skills, poor families, and our economic future. New York: Ford Foundation.

Borman, W.C., Hanson, M.A., Oppler, S.H., Pulakos, E.D., \& White, L.A. (1993). Role of early supervisory experience in supervisor performance. Journal of Applied Psychology, 78, $443-$ 449.

Borman, W.C., White, L.A., \& Dorsey, D.W. (1995). Effects of ratee task performance and interpersonal factors on supervisor and peer performance ratings. Journal of Applied Psychology, $80,168-177$.

Borman, W.C., White, L.A., Pulakos, E.D., \& Oppler, S.H. (1991). Models of supervisory job performance ratings. Journal of Applied Psychology, 76, 863-872.

Boudreau, J.W. (1991). Utility analysis for decisions in human resource management. In M.D. Dunnette \& L.M. Hough (Eds.), Handbook of industrial and organizational psychology (Vol. 2). Palo Alto: Consulting Psychologists Press.

Campbell, D.J. (1988). Task complexity: A review and analysis. Academy of Management Review, $13,40-52$. 
Campbell, A., Kirsch, I.S., \& Kolstad, A. (1992). Assessing literacy: The framework for the National Adult Literacy Survey. Washington, DC: U.S. Department of Education and Educational Testing Service.

Carnevale, A.P. (1991). America and the new economy. Washington, DC: American Society for Training and Development \& U.S. Department of Labor, Employment and Training Administration.

Carroll, J.B. (1987, February). The national assessments in reading: Are we misreading the findings? Phi Delta Kappan, 424-430.

Carroll, J.B. (1993). Human cognitive abilities: A survey of factor-analytic studies. New York: Cambridge University Press.

Carroll, J.B. (1997). Psychometrics, intelligence, and public perception. Intelligence, 24(1), 25-52.

Cascio, W.F. (1995). Whither industrial and organizational psychology in a changing world of work? American Psychologist, 50, 928-939.

Ceci, S.J., \& Liker, J.K. (1986). A day at the races: A study of IQ, expertise, and cognitive complexity. Journal of Experimental Psychology: General, 115, 255-266.

Crawford, M.P. (1962). Concepts of training. In R.M. Gagne (Ed.), Psychological principles in system development. New York: Holt, Rinehart, \& Winston.

Edgerton, R.B. (1993). The cloak of competence: Revised and updated. Berkeley: University of California Press.

Eitelberg, M.J. (1988). Manpower for military occupations. Alexandria, VA: Office of the Assistant Secretary of Defense, Force Management and Personnel.

Gardner, H. (1983). Frames of mind: The theory of multiple intelligences. New York: Basic Books.

Gazaway, R. (1969). The longest mile. New York: Doubleday.

Gordon, R.A. (1986). Scientific justification and the race-IQ delinquency model. In T.F. Hartnagel \& R.A. Siverman (Eds.), Critique and explanation: Essays in honor of Gwynne Nettler. New Brunswick, NJ: Transaction Books.

Gordon, R.A. (1997). Everyday life as an intelligence test: Effects of intelligence and intelligence context. Intelligence, 24(1), 203-320.

Gordon, R.A., Lewis, M.A., \& Quigley, A.M. (1988). Can we count on muddling through the $g$ crisis in employment? Journal of Vocational Behavior, 33, 424-451.

Gottfredson, L.S. (1980). Construct validity of Holland's occupational typology in terms of prestige, census, Department of Labor, and other classification systems. Journal of Applied Psychology, 65, 697-714.

Gottfredson, L.S. (1984). The role of intelligence and education in the division of labor. (Report No. 355). Baltimore: Johns Hopkins University, Center for Social Organization of Schools.

Gottfredson, L.S. (1985). Education as a valid but fallible signal of worker quality: Reorienting an old debate about the functional basis of the occupational hierarchy. In A.C. Kerckhoff (Ed.), Research in sociology of education and socialization (Vol. 5). Greenwich: JAI Press.

Gottfredson, L.S. (1986a). Occupational Aptitude Patterns (OAP) Map: Development and implications for a theory of job aptitude requirements (Monograph). Journal of Vocational Behavior, 29, 254-291.

Gottfredson, L.S. (Ed.). (1986b). The $g$ factor in employment [Special issue]. Journal of Vocational Behavior, 29(3).

Gottfredson, L.S. (1996, Winter). What do we know about intelligence? American Scholar, 15-30.

Gottfredson, L.S., Finucci, J.M., \& Childs, B. (1984). Explaining the adult careers of dyslexic boys: Variations in critical skills for high-level jobs. Journal of Vocational Behavior, 24, $355-373$.

Gottfredson, L.S., \& Sharf, J.C. (Eds.). (1988). Fairness in employment testing [Special issue]. Journal of Vocational Behavior, 33(3). 
Gould, S.J. (1994, November 28). Curveball [Review of The bell curve: Intelligence and class structure in American life]. New Yorker, 139-149.

Granat, K., \& Granat, S. (1978). Adjustment of intellectually below-average men not identified as mentally retarded. Scandinavian Journal of Psychology, 19, 41-51.

Gutenberg, R.L., Arvey, R.D., Osburn, H.G., \& Jeanneret, P.R. (1983). Moderating effects of decision-making/information-processing job dimensions on test validities. Journal of Applied Psychology, 68, 602-608.

Hartigan, J.A., \& Wigdor, A.K. (Eds.). (1989). Fairness in employment testing: Validity generalization, minority issues, and the General Aptitude Test Battery. Washington, DC: National Academy Press.

Harvey, R.J. (1991). Job analysis. In M.C. Dunnette \& L.M. Hough (Eds.), Handbook of industrial and organizational psychology (Vol. 2). Palo Alto: Consulting Psychologists Press.

Herrnstein, R.J., \& Murray, C. (1994). The bell curve: Intelligence and class structure in American life. New York: Free Press.

Hogan, J.C. (1991). Physical abilities. In M.C. Dunnette \& L.M. Hough (Eds.), Handbook of industrial and organizational psychology (Vol. 2). Palo Alto: Consulting Psychologists Press.

Hogan, R.T. (1991). Personality and personality measurement. In M.C. Dunnette \& L.M. Hough (Eds.), Handbook of industrial and organizational psychology (Vol. 2). Palo Alto: Consulting Psychologists Press.

Hunt, E. (1995). Will we be smart enough? A cognitive analysis of the coming workforce. New York: Russell Sage Foundation.

Hunter, J.E. (1983). Overview of validity generalization for the U.S. Employment Service. (USES Test Research Report No. 43). Washington, DC: U.S. Department of Labor, Employment and Training Administration.

Hunter, J.E. (1986). Cognitive ability, cognitive aptitudes, job knowledge, and job performance. Journal of Vocational Behavior, 29, 340-362.

Hunter, J.E., \& Hunter, R.F. (1984). Validity and utility of alternative predictors of job performance. Psychological Bulletin, 96, 72-98.

Hunter, J.E., Schmidt, F.L., \& Judiesch, M.K. (1990). Individual differences in output variability as a function of job complexity. Journal of Applied Psychology, 75, 28-42.

Jencks, C., Smith, M., Acland, H., Bane, M.J., Cohen, D., Gintis, H., Heyns, B., \& Michelson, S. (1972). Inequality: A reassessment of the effect of family and schooling in America. New York: Harper.

Jensen, A.R. (1980). Bias in mental testing. New York: Free Press.

Jensen, A.R. (1981). Straight talk about mental tests. New York: Free Press.

Jensen, A.R. (1989a). Raising IQ without increasing $g$ ? A review of The Milwaukee project: Preventing mental retardation in children at risk. Developmental Review, 9, 234-258.

Jensen, A R. (1989b). The relationship between learning and intelligence. Learning and Individual Differences, 1, 37-62.

Jensen, A.R. (1993). Test validity: $g$ versus "tacit knowledge." Current Directions in Psychological Science, 2, 910.

Jensen, A.R., \& Figueroa, R.A. (1975). Forward and backward digit-span interaction with race and IQ: Predictions from Jensen's theory. Journal of Educational Psychology, 67, 882-893.

Johnston, W.B., \& Packer, A.H. (1987). Workforce 2000: Work and workers for the 21st century. Indianapolis: Hudson Institute.

Kirsch, I.S., \& Guthrie, J.T. (1980). Construct validity of functional reading tests. Journal of Educational Measurement, 17, 81-93.

Kirsch, I.S., \& Jungeblut, A. (Eds.). (1990). Literacy: Profiles of America's young adults. Princeton: Educational Testing Service. 
Kirsch, I.S., Jungeblut, A., \& Campbell, A. (1992). Beyond the school doors: The literacy needs of job seekers served by the U.S. Department of Labor. Princeton: Educational Testing Service.

Kirsch, 1.S., Jungeblut, A., Jenkins, L., \& Kolstad, A. (1993). Adult literacy in America: A first look at the results of the National Adult Literacy Survey. Princeton: Educational Testing Service.

Kirsch, I.S., Jungeblut, A., \& Mosenthal, P.B. (1994). Moving towards the measurement of adult literacy. Paper presented at the March NCES meeting, Washington, DC.

Kirsch, I.S., \& Mosenthal, P.B. (1990). Exploring document literacy: Variables underlying the performance of young adults. Reading Research Quarterly, 25, 5-30.

Koegel, P., \& Edgerton, R.B. (1984). Black "six hour retarded children" as young adults. In R.B. Edgerton (Ed.), Lives in process: Mildly retarded adults in a large city. Washington, DC: American Association on Mental Deficiency.

Kohn, M.L., \& Schooler, C.S. (1983). Work and personality: An inquiry into the impact of social stratification. Norwood, NJ: Ablex.

Landy, F.J., Shankster, L.J., \& Kohler, S.S. (1994). Personnel selection and placement. Annual Review of Psychology, 45, 261-296.

Laurence, J.H., \& Ramsberger, P.F. (1991). Low-aptitude men in the military: Who profits, who pays? New York: Praeger.

Lubinski, D., \& Dawis, R.V. (1992). Aptitudes, skills, and proficiencies. In M.D. Dunnette \& L.M. Hough (Eds.), Handbook of industrial and organizational psychology (Vol. 3). Palo Alto: Consulting Psychologists Press.

Lubinski, D., \& Humphreys, L.G. (1997). Incorporating general intelligence into epidemiolngy and the social sciences. Intelligence, 24, 159-201.

'Matarazzo, J.D. (1972). Wechsler's Measurement and appraisal of adult intelligence (5th ed.). Baltimore: Williams \& Wilkins.

McDaniel, M.A., Schmidt, F.L., \& Hunter, J.E. (1988). Job experience correlates of job performance. Journal of Applied Psychology, 73, 327-330.

Mcllenry, J.J., Hough, L.M., Toquam, J.L., Hanson, M.A., \& Ashworth, S. (1990). Project A validity results: The relationship between predictor and criterion domains. Personnel Psychology, 43, 335-354.

Mecham, R.C., McCormick, E.J., \& Jeanneret, P.R. (1977). Position Analysis Questionnaire job analysis manual (System II). West Lafayette, IN: University Book Store.

Miller, A.R., Treiman, D.J., Cain, P.S., \& Roos, P.A. (Eds.). (1980). Work, jobs, and occupations: A critical review of the Dictionary of Occupational Titles. Washington, DC: National Academy Press.

Moffitt, T.E., Caspi, A., Harkness, A.R., \& Silva, P.A. (1993). The natural history of change in intellectual performance: Who changes? How much? Is it meaningful? Journal of Child Psychology and Psychiatry, 34, 455-506.

Mullis, I.N.S., Owen, E.H., \& Phillips, G.W. (1990). America's challenge: Accelerating academic achievement: A summary of findings from 20 years of NAEP. (ETS Report No. 19-OV-01.) Princeton: Educational Testing Service and U.S. Department of Education.

National Commission on Excellence in Education. (1983). A nation at risk: The imperative for educational reform. Washington, DC: U.S. Department of Education.

Organ, D.W. (1994). Organizational citizenship behavior and the good soldier. In M.G. Rumsey, C.B. Walker, \& J.H. Harris (Eds.), Personnel selection and classification. Hillsdale, NJ: Erlbaum.

Plomin, R., \& Petrill, S. (1997). Genetics and intelligence: What's new? Intelligence, 24(1), 53-77.

Ralph, J., Keller, D., \& Crouse, J. (1994). How effective are American schools? Phi Delta Kappan, $76,144-150$. 
Reder, S. (1995). What does NALS measure? Issues of dimensionality and construct validity. Technical report. Portland: Portland State University, National Center on Adult Literacy.

Ree, M.J., Carretta, T.R., \& Teachout, M.S. (1995). Role of ability and prior job knowledge in complex training performance. Journal of Applied Psychology, 80, 721-730.

Ree, M.J., Earles, J.A., \& Teachout, M.S. (1994). Predicting job performance: Not much more than g. Journal of Applied Psychology, 79, 518-524.

Reynolds, C.R., Chastain, R.L., Kaufman, A.S., \& McLean, J.E. (1987). Demographic characteristics and IQ among adults: Analysis of the WAIS-R standardization sample as a function of the stratification variables. Journal of School Psychology, 25, 323-342.

Kowe, D. (1997). A place at the policy table? Behavior genetics and estimates of family environmental effects on IQ. Intelligence, 24, 133-158.

Sackett, P.R., \& Ostgaard, D.J. (1994). Job-specific applicant pools and national norms for cognitive ability tests: Implications for range restriction corrections in validation research. Journal of Applied Psychology, 79, 680-684.

Schmidt, F.L., \& Hunter, J.E. (1993). Tacit knowledge, practical intelligence, general mental ability, and job knowledge. Current Directions in Psychological Science, 2, 8-9.

Schmidt, F.L., Hunter, J.E., \& Outerbridge, A.N. (1986). The impact of job experience and ability on job knowledge. work sample performance, and supervisory ratings of job performance. Journal of Applied Psychology, 71, 432-439.

Schmidt, F.L., Hunter, J.E., Outerbridge, A.N., \& Goff, S. (1988). Joint relation of experience and ability with job performance: Test of three hypotheses. Journal of Applied Psychology, 73, 46-57.

Schmidt, F.L., Ones, D.S., \& Hunter, J.E. (1992). Personnel selection. Annual Review of Psycholo$g y, 43,627-670$.

Schooler, C. (1984). Psychological effects of complex environments during the life span: A review and theory. Intelligence, 8, 259-281.

Secretary's Commission on Achieving Necessary Skills. (1991). What work requires of schools: A SCANS report for America 2000. Washington, DC: U.S. Department of Labor.

Sharf, J.C. (1988). Litigating personnel measurement policy. Journal of Vocational Behavior, 33, $235-271$.

Snow, R.E., \& Lohman, D.F. (1984). Toward a theory of cognitive aptitude for learning from instruction. Journal of Educational Psychology, 76, 347-376.

Snyderman, M., \& Rothman, S. (1988). The IQ controversy, the media and public policy. New Brunswick, NJ: Transaction Books.

Spearman, C. (1923). The nature of "intelligence" and the principles of cognition. London: Macmillan.

Spitz, H.H. (1986). The raising of intelligence: A selected history of attempts to raise retarded intelligence. Hillsdale, NJ: Erlbaum.

Sternberg, R.J., \& Wagner, R.K. (1993). The g-ocentric view of intelligence and job performance is wrong. Current Directions in Psychological Science, 2, 1-5.

Sternberg, R.J., Wagner, R.K., Williams, W.M., \& Horvath, J.A. (1995). Testing common sense. American Psychologist, 50, 912-926.

Sticht, T. (Ed.). (1975). Reading for working: A functional literacy anthology. Alexandria, VA: Human Resources Research Organization.

Sticht, T.G., Armstrong, W.B., Hickey, D.T., \& Caylor, J.S. (1987). Cast-off youth: Policy and training methods from the military experience. New York: Praeger.

Stokes, G.S., Mumford, M.D., \& Owens, W.A. (Eds.). (1994). Biodata handbook: Theory, research, and use of biographical information in selection and performance prediction. Palo Alto: CPP Books. 
Subotnik, R.F. \& Arnold, K.D. (Eds.). (1994). Beyond Terman: Contemporary longitudinal studies of giftedness and talent. Norwood: NJ: Ablex.

Thorndike, R.L. (1986). The role of general ability in prediction. Journal of Vocational Behavior, 29, 332-339.

Thorndike, R.L., Hagen, E.P., \& Sattler, J.M. (1986). The Stanford-Binet Intelligence Scale: Fourth Edition. Chicago, IL: Riverside.

U.S. Department of the Army. (1965). Marginal man and military service. Washington, DC: Author.

U.S. Department of Labor. (1970). Manual for the USTES General Aptitude Test Battery. Washington, DC: U.S. Government Printing Office.

U.S. Department of Labor. (1977). Dictionary of occupational titles (4th ed.). Washington, DC: U.S. Government Printing Office.

Venezky, R.L., Kaestle, C.F., \& Sum, A.M. (1987). The subtle danger: Reflections on the literacy abilities of America's young adults. Princeton: Educational Testing Service.

Vineberg, R., \& Taylor, E.N. (1972). Performance in four Army jobs by men of different aptitude ( $A F Q T$ ) levels: 3. The relationship of $A F Q T$ and job experience to job performance. Human Resources Research Organization Technical Report 72-22. Washington, DC: Chief of Research and Development, U.S. Department of the Army.

Wechsler, D. (1981). WAIS-R manual: Wechsler Adult Intelligence Scale-Revised. New York: Psychological Corporation.

Williams, M.V., Parker, R.M., Baker, D.W., Parikh, N.S., Pitkin, K., Coates, W.C., \& Nurss, J.R. (1995, December 6). Inadequate functional health literacy among patients at two public hospitals. Journal of the American Medical Association, 274, 1677-1682.

Wonderlic Personnel Test, Inc. (1992). Wonderlic Personnel Test and Scholastic Level Exam: User's manual. Libertyville, IL: $\Lambda$ uthor.

Wood, R.E. (1986). Task complexity: Definition of the construct. Organizational Behavior and Human Decision Processes, 37, 60-82.

\section{APPENDIX \\ USING CORRELATIONS TO ASSESS THE IMPORTANCE OF $g$}

Four ways of using correlations to assess importance are described. The second and third are the most useful in social policy analysis.

\section{Predictive Efficiency}

Predictive efficiency refers to degree of success at reducing the error in predicting individual's scores on the criterion (say, income level). The index of forecasting efficiency is one such measure, as is percentage of criterion variance "explained" by (shared in common with) the predictor. The latter, which is a squared correlation, is used in evaluating how well theoretical models "fit" the data. It also seems to be the measure of predictive importance favored by detractors of $g$ (e.g., Gould, 1994), perhaps because it (necessarily) yields the smallest-appearing estimates of importance.

However, predictive efficiency has little value in applied settings. Educators, selection psychologists, policymakers, and others who work in the realm of prac- 
tical affairs are not concerned with fully explaining particular outcomes. Instead, they usually want to know how much "bang for the buck" on a criterion they will get by changing some input by a certain amount. As already described, predictors with low predictive efficiency can yield huge effects over extended periods of time. Similarly, to take a hypothetical example, a vocational counselor would find it more useful to know that a particular counselee's SAT score gives her only a $60 \%$ chance of achieving a $\mathrm{C}$ average or better at the college she wishes to attend than to know that SAT scores account for $30 \%$ of the variation in grades in that institution.

\section{Prediction of Individuals' Odds of Success}

Little in life is guaranteed, good or bad. Like gamblers, we all have to play the odds, to the extent that we can discern them. Predictive validities can be used to show how our odds of success or failure (graduating from high school, being admitted to Harvard, bearing an illegitimate child) rise or fall depending on our traits (intelligence, grades) or circumstances (parents' income or education). In particular, correlations can be used to calculate the expected rates of criterion success for any particular range of scores on the predictor. Personnel professionals and college admissions officers, for example, use such tables to set minimum cut-off scores in hiring workers and admitting students. They cannot know for sure which particular applicants will succeed, but they can be fairly certain about the proportions who will and how those proportions rise or fall with predictive validity.

For example, consider a situation where $60 \%$ of individuals succeed. To be specific, about $60 \%$ of the working population is above the intelligence level (IQ 100) required for adequate performance as a bank teller (see Figure 1 for applicants). If a bank hired randomly, the odds of successful performance would be 1.5:1 (60:40, in Jensen, 1980, Taylor-Russell tables on p. 307). If the bank selected applicants based on a test with a predictive validity of only .3 (and hired half the applicants), the odds of success would rise to over 2:1 (69:31). Switching to a test with a validity of .45 (many are available) would raise the odds to $3: 1$ (74:26), thus doubling the original odds.

The higher the correlation between predictor and criterion, the more sharply the odds of success will diverge for the same two scores (say, IQ 85 vs. 115). As we saw, odds are especially useful in assessing the life chances of individuals at different levels of the IQ continuum. They often differ by multiples far greater than $3: 1$.

\section{Prediction of Groups' Average Performance Levels}

Odds deal with success versus failure, that is, with either meeting or failing some minimum performance level. Many institutions, however, are more interested in 
predicting average performance levels above some minimum and how much they might change under different conditions (new selection procedures, instructional strategies, nutritional supplements, and the like). This is the realm of "effect sizes" and "utility" analysis (respectively, Lubinski \& Humphreys, 1997; Boudreau, 1991).

Such calculations are of particular importance for social policy because it usually concerns itself with gradual shifts in population outcomes, favorable or unfavorable. Predictive validity need not be large for effect sizes to be substantial in both human and economic terms (Lubinski \& Humphreys, 1997). Utility analyses of alternative selection procedures make the same point. The percentage gain in aggregate worker performance that is to be expected when switching from one selection procedure to another is a direct function of their respective predictive validities. For example, a predictive validity of .4 (or .5) means that using the selection battery can achieve up to $40 \%$ (or $50 \%$ ) of the gains that would be possible by using a perfectly valid test (predictive validity of 1.0) compared with random selection (predictive validity of zero). Even much smaller increases in validity (say, from .2 to .4) often translate into thousands of dollars per hire per year (see Boudreau, 1991, for an extended discussion of utility analyses in personnel selection).

\section{Relative Importance}

The importance of a predictor is often also judged by comparing its validity with that of other predictors. The predictor with the tighter link to important outcomes is, prima facie, the more important. More formally, a set of such correlations can be mathematically modeled to estimate the independent effects of each predictor. Path analyses that do so were reviewed earlier.

However, simple comparisons of predictors are also useful in the current context. Socioeconomic background (parental income, education, poverty) is widely presumed to be an important cause of different life outcomes, so it can serve here as a benchmark for relative importance. If the correlations for $g$ equal or exceed those for social class, then $g$ would appear to be important as well. Indeed, as we saw, $g$ is quite important by this measure (cf. Gordon, 1997).

Finally, it is important to realize that the same validity coefficient may be of little use for one purpose (accurately predicting an individual's behavior) and yet quite powerful for another (predicting rates of behavior in different groups). Also, a panoply of even small validities that might be inconsequential individually can cumulate for enormous impact over an individual's lifetime. An analogy is the small but inexorable odds favoring the house in casino gambling (Gordon et al., 1988). 